Portland State University

PDXScholar

Summer 8-28-2013

\title{
A Parametric Study on Power Variation for Model Wind Turbine Arrays
}

Dominic DeLucia

Portland State University

Follow this and additional works at: https://pdxscholar.library.pdx.edu/open_access_etds

Part of the Energy Systems Commons

Let us know how access to this document benefits you.

\section{Recommended Citation}

DeLucia, Dominic, "A Parametric Study on Power Variation for Model Wind Turbine Arrays" (2013).

Dissertations and Theses. Paper 1120.

https://doi.org/10.15760/etd.1120

This Thesis is brought to you for free and open access. It has been accepted for inclusion in Dissertations and Theses by an authorized administrator of PDXScholar. Please contact us if we can make this document more accessible: pdxscholar@pdx.edu. 
A Parametric Study on Power Variation for Model Wind Turbine Arrays

by

Dominic DeLucia

A thesis submitted in partial fulfillment of the requirements for the degree of

\author{
Master of Science \\ in \\ Mechanical Engineering
}

Thesis Committee:

Raúl Bayoán Cal, Chair

Gerald Recktenwald

Mark M. Weislogel

Portland State University

2013 


\begin{abstract}
The siting of wind turbines becomes important when power must be maximized and land area is limited. Wind tunnel experiments were performed on model wind turbine arrays to understand how siting affects power output. Simultaneously measuring the torque and the angular velocity of the rotor yields a direct measurement of the fluid mechanical power extracted by the wind turbines. This experiment varied the parameters of alignment, height, spacing, and the rotational direction of the wind turbines and used mechanical torque sensors to measure the power output at multiple turbine locations. For a 4 X 3 array, the power was calculated at the center turbine in each of the rows. Changing the layout of the wind turbine array affected the power output; power measurements showed that the assumption of using the mean velocity to calculate the power coefficient might not be valid when there are large velocity fluctuations. Variations in wind farm efficiency ranging from 55 percent to 90 percent were observed in the 13 different layouts. This highlights the importance of studying the effect that wind farm layout has on power.
\end{abstract}




\section{Table of Contents}

Abstract $\quad$ i

List of Tables $\quad$ iv

List of Figures $\quad$ v

1 Introduction 1

1.1 Energy extraction from the wind .............. 4

2 Methods 11

2.1 The wind tunnel ......................... 11

2.2 Model wind turbines . . . . . . . . . . . . . . . . . 13

2.3 Particle Image Velocimetry . . . . . . . . . . . . . . . . . 15

2.4 Torque sensor . . . . . . . . . . . . . . . . . . 17

2.5 Measuring angular velocity . . . . . . . . . . . . . . . 21

2.6 Experimental configurations .................. 23

$\begin{array}{llr}3 & \text { Results } & 27\end{array}$

3.1 Spacing Variation . . . . . . . . . . . . . . . 27

3.2 Staggered Configuration . . . . . . . . . . . . . . . . . 30

3.3 Clockwise and Counterclockwise Configuration . . . . . . . . . . 33

3.4 Height Variation . . . . . . . . . . . . . . . . 35

3.5 The Power Coefficient . . . . . . . . . . . . . 36

3.6 Wind Farm Efficiency . . . . . . . . . . . . . . . . . . . 41 
4 Conclusion

References 


\section{List of Tables}

2.1 In Cases 1A-1D variables $S_{X}$ and $S_{Z}$ define the downstream and transverse spacing for Figure 2.10. The rotor rotation was clockwise and the mast height was 1D. . . . . . . . . . . . . . . . . 23

2.2 In Cases $2 \mathrm{~A}-2 \mathrm{C}$ variables $S_{X}$ and $S_{Z}$ define the downstream and transverse spacing for Figure 2.11. The rotor rotation was clockwise and the mast height was $1 \mathrm{D} . \ldots \ldots \ldots \ldots \ldots$

2.3 In Cases 3A-3C variables $S_{X}$ and $S_{Z}$ define the downstream and transverse spacing for Figure 2.10. The rotor rotation vaired depending on the Case and Row. . . . . . . . . . . . . . . . . . . . .

2.4 In Cases $4 \mathrm{~A}-4 \mathrm{C}$ variables $S_{X}$ and $S_{Z}$ define the downstream and transverse spacing for Figure 2.10. The mast height vaired depending on the Case and Row. . . . . . . . . . . . . . . . . . . 


\section{List of Figures}

1.1 Control area defined by a streamtube surrounding a turbine disk plane. 6

2.1 Portland State University wind tunnel facility. The test section is visible in the center and the flow enters from the left through the contraction of the duct. . . . . . . . . . . . . . . . . 11

2.2 Typical setup of wind turbines placed $6 \mathrm{D}$ apart downstream. PIV data was collected $0.5 \mathrm{D}$ upstream of the rotor. The model turbines are scaled down 850 times. . . . . . . . . . . . . . . . . 12

2.3 View of the upstream inflow conditioning techniques. Small chains are on the floor and the passive grid and strakes are at the test section inlet. 13

2.4 Image of Case 1D: the rows and columns have 3D and 1.5D spacing

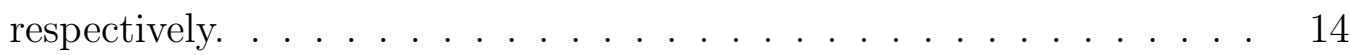

2.5 Diagram of the torque sensor. . . . . . . . . . . . . . 17

2.6 Image of the rear of the torque sensor. Strain gauges are attached to the horizontal bronze strip. . . . . . . . . . . . . . . . . . . . . . . . . 17

2.7 Image of the the aluminum block and the bridge sensor. . . . . . . . . 19

2.8 To calibrate the torque sensor, a weight was placed in the basket and the torque was correlated with the voltage signal from the torque sensor. 19

2.9 Plot of the linear best-fit torque calibration curve where $\mathrm{T}=5.717 \times$ $10^{-3} V-3.807 \times 10^{-3} \mathrm{~N}-\mathrm{m}$. The error bars represent $\pm 3 \%$ uncertainty in the data. . . . . . . . . . . . . . . . . . . 20 
2.1010 cases are a 3 by 4 wind turbine array. The spacing variables $S_{X}$ and $S_{Z}$ change in Cases 1A-1C. Power measurements were obtained at the centerline in all 4 rows. Cases $3 \mathrm{~A}-3 \mathrm{C}$ and $4 \mathrm{~A}-4 \mathrm{C}$ had the same spacing as Case 1A. . . . . . . . . . . . . . .

2.11 Depiction of the staggered wind turbine arrays. The variables $S_{1}$ and $S_{2}$ represent the offset distance from the centerline and $S_{X}$ and $S_{Z}$ downstream and transverse spacing respectively. . . . . . . . . . . . . 24

2.12 Description of the centerline profile of Case $4 \mathrm{~A}-4 \mathrm{C} . H_{1}$ represents the short mast and $H_{2}$ represents the tall mast. The position of the tall and short masts changed for each of the three cases. . . . . . . . .

3.1 Mechanical power as a function of angular velocity. The error bar represents the $\pm 4 \%$ uncertainty of the data. . . . . . . . .

3.2 Power as a function of angular velocity comparing the power output of the 4 rows in Case 2A and Case 2B. . . . . . . . . . . . . . . . . 31

3.3 Power as a function of angular velocity comparing the power output of the 4 rows in Case $2 \mathrm{C} \ldots \ldots . \ldots 32$

3.4 Power as a function of angular velocity comparing the power output of the 4 rows in Case 3A, 3B, and 3C. . . . . . . . . . . . . 34

3.5 Power as a function of angular velocity comparing the power output of the 4 rows in Case $4 \mathrm{~A}, 4 \mathrm{~B}$ and $4 \mathrm{C} \ldots \ldots \ldots$ 
3.6 Power coefficient as a function of tip-speed ratio comparing the turbine efficiency of the front row turbines from all the cases. . . . . . . . . . 37

3.7 Power coefficient as a function of tip-speed ratio comparing the turbine

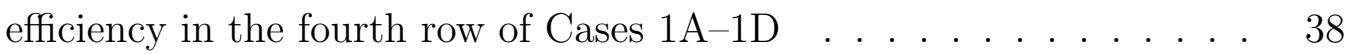

3.8 Power coefficient as a function of tip-speed ratio comparing the turbine efficiency in the fourth row of Cases $2 \mathrm{~A}-2 \mathrm{C}$. The fourth row of Case $1 \mathrm{~A}$ is represented by the $(\triangle)$ and added for comparison. . . . . . .

3.9 Power coefficient as a function of tip-speed ratio comparing the turbine efficiency in the fourth row of Cases 3B and 3C. The fourth row of Case $1 \mathrm{~A}$ is represented by the $(\triangle)$ and added for comparison. . . . . . .

3.10 Power coefficient as a function of tip-speed ratio comparing the turbine efficiency of the fourth rows of Cases $4 \mathrm{~A}-4 \mathrm{C}$. The fourth row of Case $1 \mathrm{~A}$ is represented by the $(\triangle)$ and added for comparison. . . . . . .

3.11 Overall wind farm efficiency of the 13 experimental layouts. Error bars indicate $\pm 5 \%$ uncertainty in the data. . . . . . . . . . . 


\section{1 \\ Introduction}

In 1891 the Danish built the first wind turbine to generate electricity. They continued to improve their wind technology during the early to mid-twentieth century (Şahin, 2004). During the oil crisis in the 1970's, the U.S. wind industry began in California and by 1986 more than $1.2 \mathrm{GW}$ of wind power was installed. At the time it represented about $90 \%$ of global installations (USDOE, 2008). Policy changes in the 1980s led to an abrupt halt in the U.S. wind energy industry while the global wind industry continued to grow. By the year 2000 Europe had more than 12 GW installed versus $2.5 \mathrm{GW}$ in the U.S. (USDOE, 2008). Currently, the use of wind energy is increasing rapidly and the United States has set a goal to meet $20 \%$ of domestic electrical power with wind energy by the year 2030 (USDOE, 2008). According to the U.S. Department of Energy, the U.S. was producing 11.6 GW of electrical power in 2006; by 2030 that figure is estimated to increase to $300 \mathrm{GW}$. Consequently, wind farms will grow in size to meet the increase in production. Individual wind turbines need to operate more efficiently, and wind farms will need to be configured to maximize their output as an electricity generating system. With the energy generated by wind farms increasing at a rapid rate, wind farms are becoming larger and turbines in the array may begin to interfere with each other. Conditions such as terrain and atmospheric variability can cause the wind turbines to operate less efficiently. The wakes from the wind turbines can affect the amount of power extracted by the wind turbines operating in the wake. To site wind turbines with the goal of maximizing their power output, it is necessary to study the interactions between the turbines. 
Wind energy could be one of the oldest power sources in the world; however, the aerodynamics governing the power extracted by wind turbines is not fully understood (Vermeer, Sørensen, \& Crespo, 2003). One of the greatest challenges to the understanding of power extraction from the wind is turbulence and how energy is transported in the atmospheric boundary layer. Wind turbine wakes are generally divided into two categories: the near wake and the far wake. The near wake is where the influence of the separate rotor blades can be distinguished. In an offshore wind farm it was observed that the power deficit behind a wind turbine is strongly dependent on the wind turbine spacing and as turbulence intensity increases, the power deficit decreases (Hansen, Barthelmie, Jensen, \& Sommer, 2012). There is a gradual transition between the near wake and the far wake. This study will focus on how wake effects propagate downstream, influencing the power extracted by wind turbines in a model wind farm.

In a wind-tunnel experiment (Chamorro \& Porté-Agel, 2009), it was shown that spatial distribution of the velocity deficit and the turbulence intensity are important factors that affect power generation in a wind farm. The study investigated the wake of a model wind turbine placed in a boundary layer that developed over both rough and smooth surfaces. In another study (Bartl, Pierella, \& Sætran, 2012), the local velocity deficit and the turbulence intensities in the wake behind an array of two model wind turbines was studied. It was shown that the velocity profile of the unobstructed turbine in the front row is similar to the velocity distribution at 5 rotor-diameters 
(5D) downstream in the wake of the second turbine. In an experimental study using two model wind turbines (Adaramola \& Krogstad, 2011), the wake interference effect on the performance of the downstream wind turbine was investigated. The study found that separation distance and the power extracted from the upstream turbines affects the performance of the downstream turbine.

Full scale wind turbines operate about 100 meters above the ground. In this region of the atmospheric boundary layer wind turbines are directly influenced by the Earth's surface, including frictional drag forces, evaporation and transpiration, heat transfer, pollution emissions, and terrain-induced flow modifications (Şahin, 2004). During the course of the day a wind turbine experiences three conditions of the atmospheric boundary layer: neutral, stable, and unstable conditions. In the neutral atmospheric boundary layer, the temperature of the surface is equal to the temperature of the air. Wind speeds in the atmosphere can fluctuate rapidly; for this reason statistics are used to describe the turbulence. There are many statistical descriptions of turbulence (Pope, 2000) and (Tennekes \& Lumley, 1973). Some parameters that effect the power production of a wind turbine can be modeled in wind tunnels. Surface roughness causes frictional drag is in the boundary layer. Surface roughness is modeled using small roughness elements added to the floor of the wind tunnel.

Traditionally, only the mean hub height velocity is considered when calculating the power available in the wind; the effects of turbulence and surface roughness are neglected. Some simple descriptions of turbulence are turbulence intensity and gust 
factors (Greenway, 1979). Wagner et al. (2009) identified the influence of wind shear and turbulence on wind turbine performance by simulating wind speed measurements at different heights over the sweep of the rotor. It was found that electrical power correlates significantly better to the equivalent wind speed than to the single point hub-height wind speed.

In a wind farm, the first row of wind turbines extracts a considerable amount of the kinetic energy from the wind, resulting less energy available for the following rows. Important parameters such as the distance between the turbines, the layout of the wind turbines, and the power extracted by the wind farm need to be researched to help design better wind farms. Therefore, this study investigates the differences in power extracted by model wind farms in a wind tunnel experiment that changes the spacing, height, the alignment of the wind turbines, and the rotational direction of the rotors.

\subsection{Energy extraction from the wind}

The power in the wind is the kinetic energy per time extracted through the plane

of the rotor. It is quantified in Equation (1.1) by combining the kinetic energy, $E=\frac{1}{2} \dot{m} U^{2}$ and the mass flow rate of air, $\dot{m}=\rho U A$ to yield,

$$
P=\frac{1}{2} \rho A U^{3}
$$


The power $P$ is a function of the cube of the wind velocity $U$, the density of the air $\rho$, and the frontal area of the rotor $A$. Wind turbines cannot extract all of the energy present in the wind; otherwise, the energy in the wind would be reduced to zero: No more energy would flow through the wind turbine and the air would simply flow around. The power in the turbine is derived from the air that passes through the rotor and undergoes a change in velocity. In 1919, Albert Betz derived from momentum theory a fluid mechanical limit for the efficiency of a wind turbine. Energy extraction from the wind is mainly described in terms of this theory, which is a two-dimensional model defines a streamtube and calculates the power over the area of an actuator disk. This theory assumes uniform flow with no energy passing the boundary of the streamtube. Burton et al. described the actuator disk concept in the study of the aerodynamic behavior of wind turbines and the energy extraction process. The actuator concept defines a boundary between the mass of air passing through the rotor and the unaffected flow creating a streamtube. It follows that the energy contained in the wind is described in terms of kinetic energy and the pressure energy. A depiction of the streamtube concept is shown in Figure 1.1. The continuity equation,

$$
\rho A_{i n} U_{i n}=\rho A_{h} U_{h}=\rho A_{w} U_{w}
$$

Equation (1.2), requires the mass flow rate along the streamtube to be constant if the flow is incompressible. The inflow velocity $U_{\text {in }}$ is defined in the direction parallel to 
the hub and ground and perpendicular to the rotor. The cross-sectional area of the streamtube is a small distance in front of the actuator disk $A_{i n}$, and $\rho$ is the density of air. $A_{h}$ is the area of the actuator disk and $U_{h}$ is the average hub height velocity at the rotor. Downstream from the actuator disk is the wake velocity, $U_{w}$ and the cross-sectional area of the wake, $A_{w}$. The actuator is a physical model that allows for discontinuities in the governing equations (Sørensen \& Myken, 1992).

At a certain distance in front of the actuator disk, the wind speed will begin to decrease continuously; there is no instantaneous velocity change at the disk (Burton et al., 2001). Since Equation (1.2) requires the mass flow rate along the streamtube be constant, the decrease in velocity causes the area of the wake to expand downstream from the disk (Burton et al., 2001).

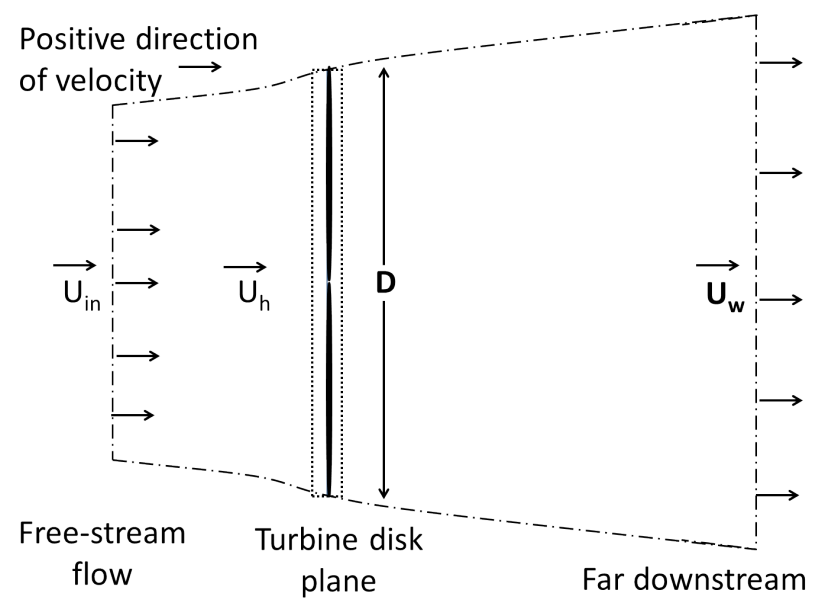

Figure 1.1: Control area defined by a streamtube surrounding a turbine disk plane. 
The performance of a wind turbine is described by

$$
C_{p}=\frac{P}{\frac{1}{2} \rho U_{h}^{3} A_{h}},
$$

the nondimensional power coefficient. It is defined as the actual power, $P$, extracted by the rotor normalized by the maximum power contained in the streamtube, where $U_{h}$ is the hub height velocity at the rotor, and $A_{h}$ is the area of the rotor. Equation (1.3) represents the turbine efficiency. As previously stated, it is not possible for a wind turbine to extract all of the energy from the wind. Betz applied the momentum theory described above and determined that a power coefficient of $C_{p}=0.593$ is the maximum that can be achieved. This limit occurs because the air stream needs to expand as it approaches the rotor (Burton et al., 2001).

The power coefficient is often plotted against the tip speed ratio, $\lambda$ given by:

$$
\lambda=\frac{D \omega}{2 U_{h}}
$$

where $\omega$ is the rotational speed of the turbine; $D$ is the diameter of the rotor and is normalized by the approaching wind speed. In practice the hub height velocity $U_{h}$, is the mean velocity averaged over the area of the rotor. In full-scale wind farms the average hub height velocity is defined by, 


$$
U_{h}=\frac{2}{A_{h}} \int_{H-r}^{H+r} U(z)\left(r^{2}-H^{2}+2 H z-z^{2}\right)^{\frac{1}{2}} d z
$$

where $H$, is the height of the tower, $r$ is the radius of the rotor, and $U(z)$ are the velocities at several heights located in front of the rotor (Wharton \& Lundquist, 2012). In model wind farm experiments the hub-height velocity is averaged in a similar manner (Kang \& Meneveau, 2010).

Full scale turbine blades can reach a maximum $C_{p}$ in the range of 0.45 to 0.50 , this is well below the Betz limit of 0.593 . The rotor blades will begin to stall in the area near the hub when the rotor blades are operating at lower than designed tip-speed ratios. At higher than designed tip-speed ratios, excess drag will decrease the power performance (Adaramola \& Krogstad, 2011). High levels of turbulence may also effect the efficiency of the turbine blades.

Studies of full-scale wind farms have shown that the interference of the wake affects the performance characteristics of the turbines, and that the power losses from the turbine operating in the wake are significant (Adaramola \& Krogstad, 2011). The first row of wind turbines extract power from the air stream, leaving less kinetic energy available for the downstream turbines. In large wind farms it is important to understand the interactions of the atmosphere and the wind turbine array. A wind tunnel experiment (Cal et al. 2010) studied the horizontally averaged structure of a boundary layer over an array of model wind turbines. The study found that in 
a model wind farm the power extraction is dominated by the vertical transport of kinetic energy (Cal et al. 2010). The wake recovers by entraining energy from the freestream above the wind farm. A study of two offshore wind farms with different layouts and turbine spacing were used to quantify the relationship between wind turbine spacing and wake losses (Barthelmie et al. 2010). Observations from this study suggest that the wake center is preserved as it moves through the wind farm. The study also used a computer model simulation to compare wake width and normalized power output. The models were able to capture wake width to some degree, and some models also captured the decrease of power output moving through the wind farm.

Kang and Meneveau (2010) showed that directly measuring the torque from model wind turbines scales up better than measuring the electrical power output from model turbines. Due to the scale difference, the internal losses of the small electrical motors do not represent the larger turbines accurately. For model wind turbines directly measuring the mechanical power output is expected to scale up more reliably than the electrical output from the motors (Kang \& Meneveau, 2010).

The wind farm efficiency can be defined as

$$
\eta=\frac{P_{\text {wake }}}{P_{\text {freestream }}},
$$

where $P_{\text {wake }}$ is the power extracted by the turbines in the wind farm operating in 
the wake and $P_{\text {freestream }}$ is the maximum power that would be produced if all of the turbines were operating under free-stream conditions (Adaramola \& Krogstad, 2011). 


\section{2 \\ Methods}

\subsection{The wind tunnel}

The present experimental investigation was performed in the wind tunnel at Portland State University. The wind tunnel is a closed-return boundary-layer wind tunnel equipped with an external 75-horsepower motor. The motor drives a propeller to a maximum speed of $800 \mathrm{rpm}$ to generate the flow, reaching velocities in the range of 2 to $40 \mathrm{~m} / \mathrm{s}$. The test section is $5 \mathrm{~m}$ long by $1.2 \mathrm{~m}$ wide, and the ceiling was held constant at $0.8 \mathrm{~m}$ height to generate a zero pressure gradient throughout the flow. The walls and ceiling of the test section are glass to allow full optical access inside the test section. Figure 2.1 is a depiction of the wind tunnel facility. The air travels through stainless steel ducts that are thermally and acoustically insulated. The corners are fitted with constant-area-type turning vanes that keep the flow together.

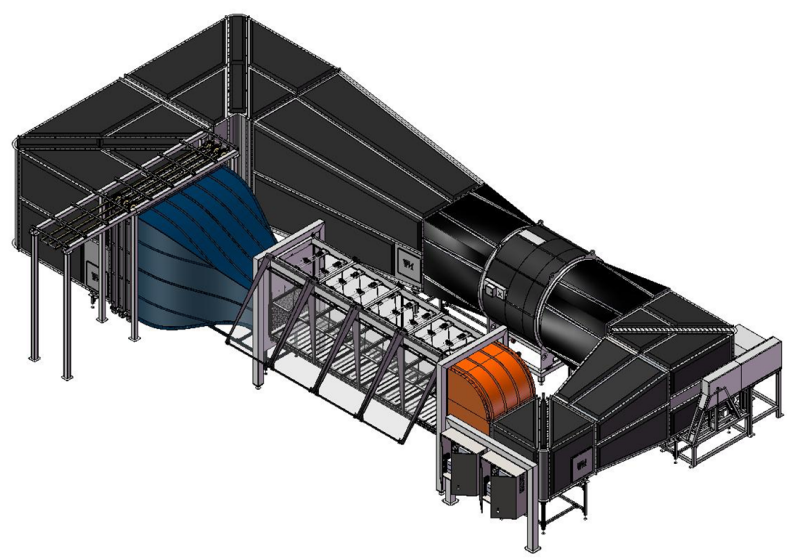

Figure 2.1: Portland State University wind tunnel facility. The test section is visible in the center and the flow enters from the left through the contraction of the duct. 


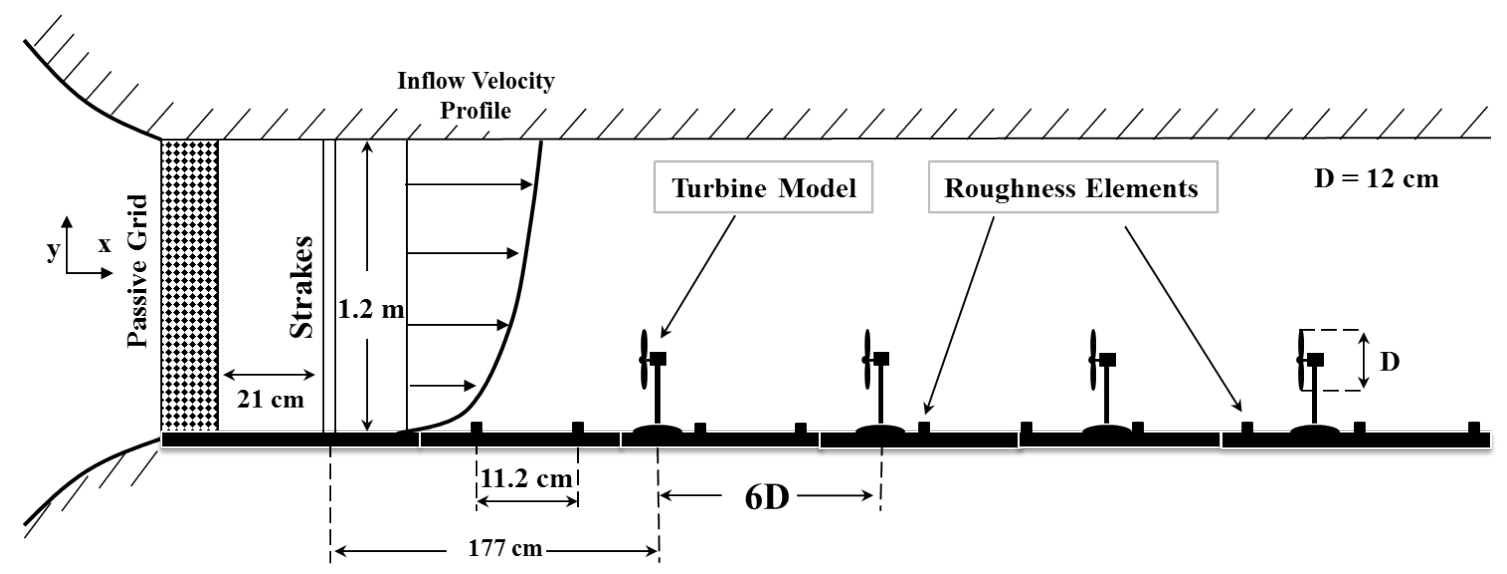

Figure 2.2: Typical setup of wind turbines placed 6D apart downstream. PIV data was collected $0.5 \mathrm{D}$ upstream of the rotor. The model turbines are scaled down 850 times.

The flow is conditioned through a stainless steel honeycomb with one screen of 24 mesh per inch and two 32-mesh per-inch screens. The flow then passes through an asymmetric contraction, in which the duct contracts from $2.4 \mathrm{~m}$ by $2.4 \mathrm{~m}$ to $0.8 \mathrm{~m}$ by $1.2 \mathrm{~m}$ by means of wall that follows a fifth-order polynomial curve. Figure 2.2 shows the experimental setup inside the test section. The flow enters the test section through a passive grid having twelve rods with wiglets attached to introduce low levels of turbulence. The inflow turbulence intensity at the hub height was $15 \%$.

The experiment was conducted under neutral conditions with a nominal ambient temperature of $21^{\circ} \mathrm{C}$. Inside the test section the flow was conditioned again with 9 acrylic strakes. The strakes add shear to the flow to generate a characteristic velocity profile found in the atmospheric boundary layer. Small chains placed $11.2 \mathrm{~mm}$ apart in the streamwise direction to add surface roughness. The chains are $5 \mathrm{~mm}$ wide and 
have a vertical profile of $3 \mathrm{~mm}$. Figure 2.3 is a picture of the strakes and surface roughness. More details on the strakes and surface roughness can be found in Cal et al. (2010).

\subsection{Model wind turbines}

The experiment consisted of 10 to 12 three-bladed model wind turbines arranged in arrays with different spacing. The turbines' nacelles were DC motors (Faulhaber 1331T012SR) measuring $3.1 \mathrm{~cm}$ long with a diameter of $13 \mathrm{~mm}$. The motors were run as generators, mounted on steel masts with an outside diameter of $0.953 \mathrm{~cm}$. The masts were threaded and screwed into supports constructed of steel $0.6 \mathrm{~cm}$ thick. Two tower heights were used in the experiment. The overall length from the floor of the wind tunnel to the hub height was

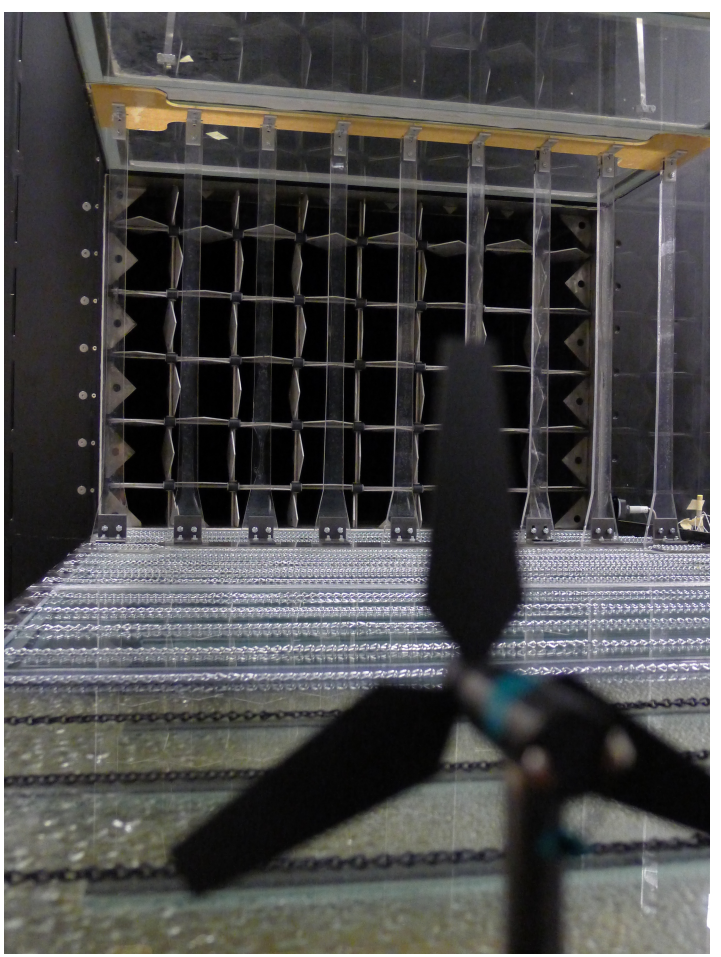

Figure 2.3: View of the upstream inflow conditioning techniques. Small chains are on the floor and the passive grid and strakes are at the test section inlet. 


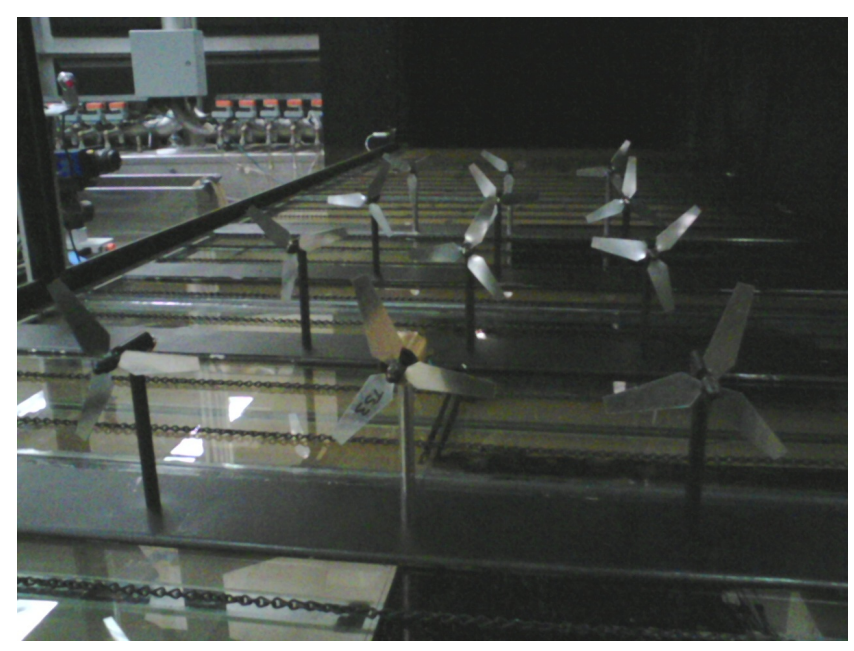

Figure 2.4: Image of Case 1D: the rows and columns have $3 \mathrm{D}$ and $1.5 \mathrm{D}$ spacing respectively.

$12 \mathrm{~cm}$ for the short masts and $18 \mathrm{~cm}$ for the tall masts. The rotor blades were attached to the motors using a $1.5 \mathrm{~mm}$ domed-nut prop adapter. The prop adapter has a $1.5 \mathrm{~mm}$ shaft adapter that fits the $1.5 \mathrm{~mm}$ shaft of the motor. The adapter has two set screws to fix the rotor to the motor shaft, ensuring that there is no slip. For the wind turbines in this experiment, the rotor blades of $6 \mathrm{~cm}$ radius were fabricated from $0.001 \mathrm{~m}$ thick steel sheet. A total of 18 blades were twisted using a jig, from approximately $21^{\circ}$ at the hub and tapering to approximately $16^{\circ}$ at the tips. Six of the blades were twisted to rotate in the counterclockwise direction. All of the blades were measured: the maximum deviation from the desired twist angle was $2^{\circ}$.

Thirteen wind turbine arrays with four rows of wind turbines were placed on the floor of the wind tunnel. Figures 2.4 is a photo one of the of layouts used in the 
experimental study. The wind farm layout in Figure 2.4 has 3D downstream spacing and $1.5 \mathrm{D}$ transverse spacing. Four wind turbines were fitted with torque sensors and placed in the center of each row.

\subsection{Particle Image Velocimetry}

Particle image velocimetry (PIV) measurements were performed upstream from the wind turbines fitted with torque sensors in order to characterize the inflow velocity at each turbine. The PIV system used a double pulse Nd:YAG laser with a time of 120 $\mu \mathrm{s}$. The laser light was routed around the wind tunnel and focused on a cylindrical lens to create a light sheet $1.0 \mathrm{~mm}$ thick in front of the wind turbine. The walls and the floor were painted black to minimize reflected light.

The PIV system was calibrated before measuring the velocity at each location. The calibration target was $120 \mathrm{~mm}$ by $120 \mathrm{~mm}$ and was composed of white dots with a white square to locate the center. The location of the center was measured from the plane of the rotor to the center of the white square. Two calibration images were taken from different perspectives and the expected uncertainty of the velocity vectors in the $(\mathrm{x}, \mathrm{y})$ plane from the PIV measurements is $\pm 2 \%$. To collect velocity measurements the recorded PIV images are divided into small interrogation windows. During a small time interval the particles in each interrogation window become displaced by the wind. To calculate the particle displacement, a cross-correlation based on a Fast

Fourier Transformation was performed for the two interrogation windows. Where 
power measurements were collected, 750 PIV images were gathered upstream from the wind turbine and used to calculate mean and instantaneous velocity. For the post-processing of the recorded data, a MATLAB program was written to calculate the mean hub-height velocity and turbulent intensity in front of the wind turbines where power measurements were made. Throughout the experiment the average inflow free-stream velocity at the front row of all the wind turbine arrays was held constant at $5.5 \mathrm{~m} / \mathrm{s}$.

Particle Image Velocimetry measurements were collected at $0.5 \mathrm{D}$ upstream of the wind turbines along the centerline in each row. Velocities were measured while the turbines were loaded for peak power output. The mean streamwise hub-height velocity was calculated using Equation (1.5). $U_{\infty}=5.5 \mathrm{~m} / \mathrm{s}$ at the inlet of the front row. Turbulence intensity is defined as

$$
T I=\frac{\left\langle u^{2}\right\rangle^{\frac{1}{2}}}{\left\langle U_{h}\right\rangle},
$$

where $\left\langle U_{h}\right\rangle$ is the average hub-height velocity calculated from Equation (1.5) and $u$ is the instantaneous velocity fluctuations calculated over 750 samples. The mean hub-height velocity was $3.39 \mathrm{~m} / \mathrm{s}$ and calculated using Equation (1.5). The turbulent intensity was $15 \%$ and was calculated using Equation (2.1). A value of $15 \%$ is a low turbulence level which is expected since the active grid was turned off for all of the measurements. 


\subsection{Torque sensor}

The torque sensors were constructed in house. A diagram of the torque sensing system is shown in Figure 2.5. A DC micromotor (Faulhaber 1331T012SR) freely rotates on two VXB ball bearings inside a brass cylinder with thin walls. The cylinder is $33 \mathrm{~mm}$ in length with an outside diameter of $25.4 \mathrm{~mm}$ and an inside diameter of $24 \mathrm{~mm}$. The bearings have an inner ring $13 \mathrm{~mm}$ in diameter, which holds the motor, and an outer ring $24 \mathrm{~mm}$ in diameter that is fixed to the inside of the brass cylinder. The ball

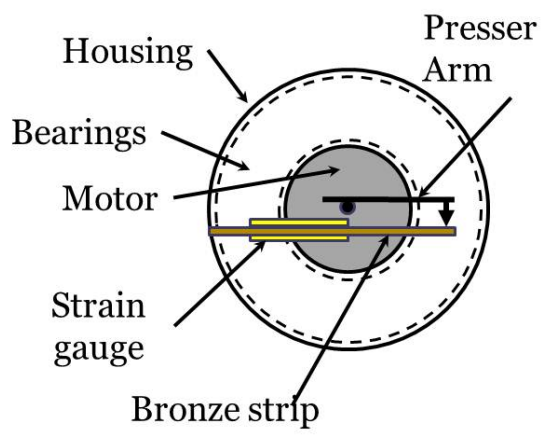

Figure 2.5: Diagram of the torque sensor.

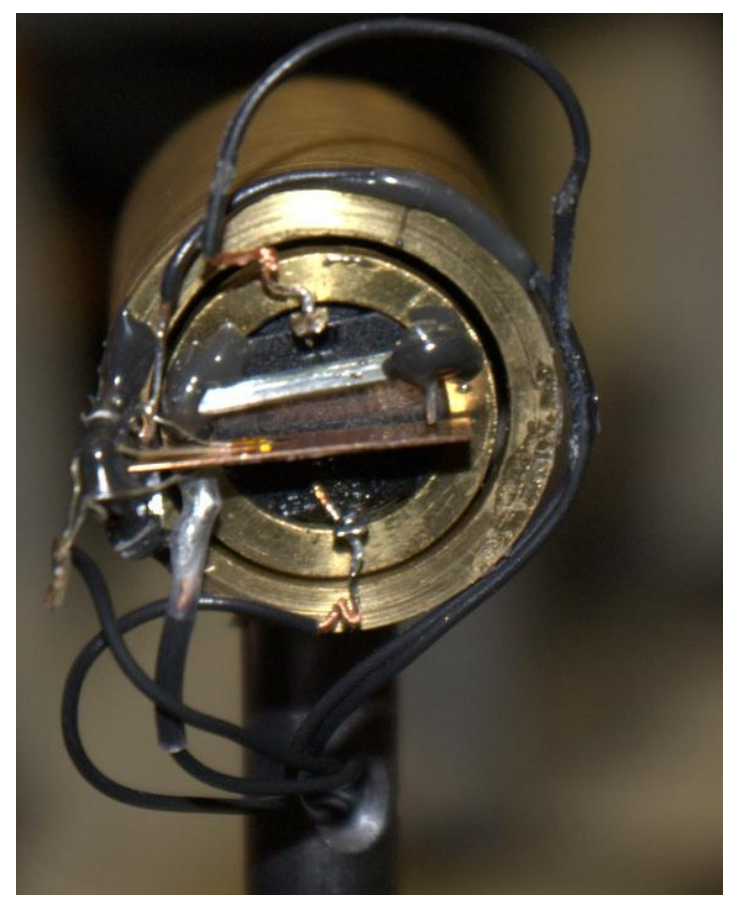

Figure 2.6: Image of the rear of the torque sensor. Strain gauges are attached to the horizontal bronze strip. 
bearings are lightly lubricated chrome steel. Figure 2.6 shows brass rings fitted to the back of the motor and the surrounding cylinder. Attached to the inner brass ring is a cross-brace that supports a small pressing rod. The other brass ring is mounted to the back of the cylinder with a tiny aluminum bracket attached. The aluminum bracket holds a 28-gauge phosphorous bronze (alloy 510) strip $20 \mathrm{~mm}$ long and $5 \mathrm{~mm}$ wide. Affixed to the surfaces of the strip are two small $120 \Omega$ linear strain gauges (OMEGA SGD-3/120-LY11). The bronze strip deflects under an applied torque.

Measuring the torque requires the correlation of the strain gauge voltage to an applied weight. In this experiment, when torque was applied to the motor, a voltage was generated across a Wheatstone bridge electrical circuit. The circuit was constructed with four $120 \Omega$ linear strain gauges. Two gauges were mounted on the surfaces of the bronze strip and the other two were fixed to a $10 \mathrm{~cm}$ by $10 \mathrm{~cm}$ aluminum cube. Figure 2.7 shows the aluminum block and the Omega Bridgesensor signal amplifier. The bridge voltage from the Wheatstone bridge was conditioned and amplified with an OMEGA DMD-465 Bridgesensor.

For this experiment, the torque sensor was calibrated using a dead weight method. A small horizontal rod was attached to the front of the motor. Known masses ranging from $1 \mathrm{~g}$ to $5 \mathrm{~g}$ were placed at the end of the small horizontal rod. The torque to overcome the static friction of the bearings was determined experimentally by placing weights at the end of a small rod fixed to the center ring of the bearings. The torque applied to the motor that overcame static friction of the ball bearings was recorded. 
It was determined that $1.3 \times 10^{-4} \mathrm{~N}-\mathrm{m}$ of torque is required to overcome the static friction of the bearings. Figure 2.8 depicts the method of calibration. The moment arm is $20 \mathrm{~mm}$ in length, which generates a torque on the motor when weights are placed in the basket. The torque was calculated from the weight multiplied by the length of the moment arm. A calibration was performed each time the wind turbine fitted with the torque sensor was moved.

A correlation between the applied torque and bridge voltage was obtained each

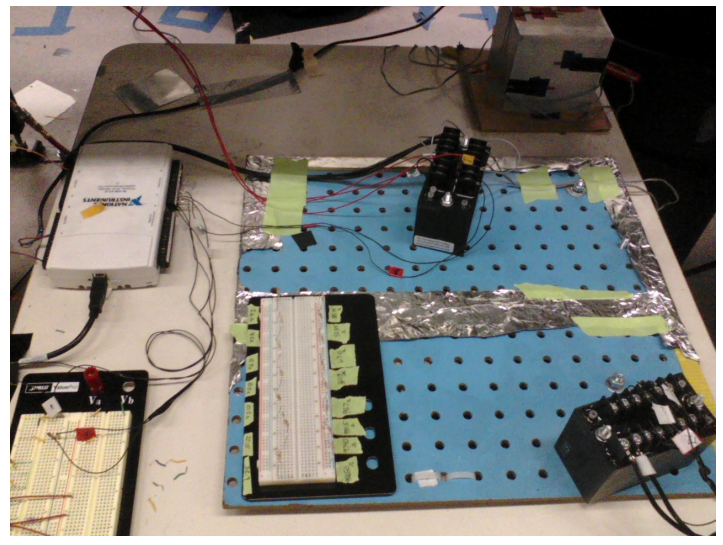

Figure 2.7: Image of the the aluminum block and the bridge sensor.

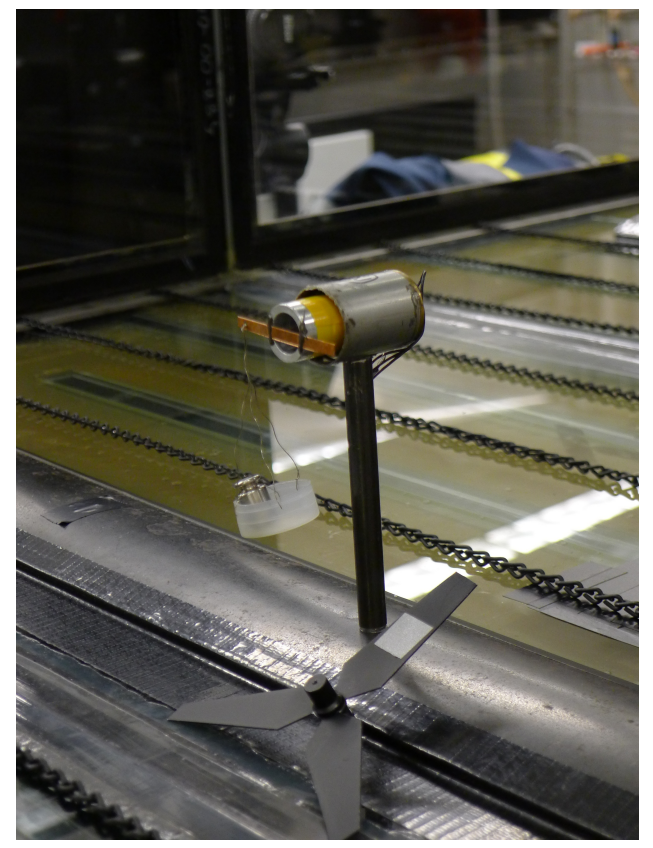

Figure 2.8: To calibrate the torque sensor, a weight was placed in the basket and the torque was correlated with the voltage signal from the torque sensor. 


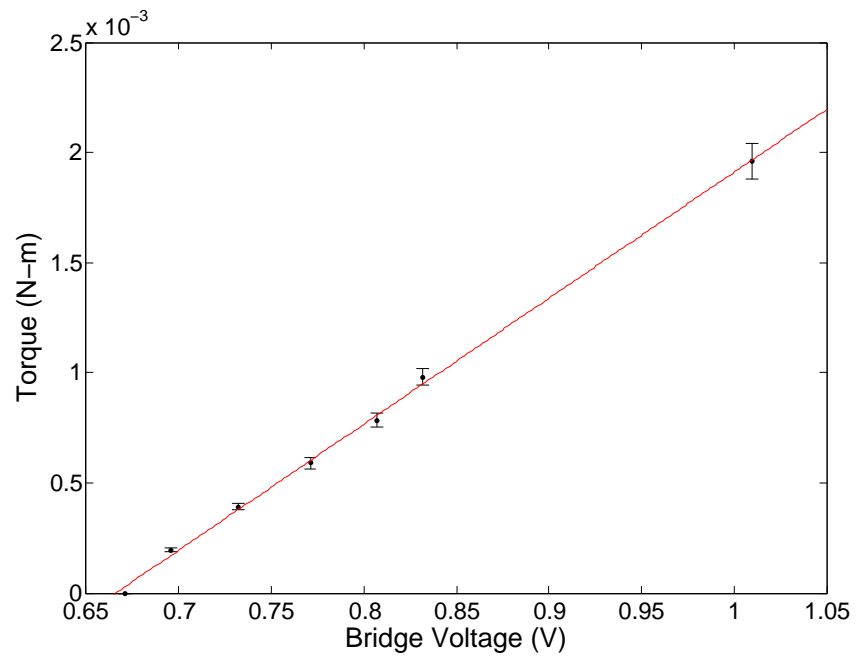

Figure 2.9: Plot of the linear best-fit torque calibration curve where $\mathrm{T}=5.717 \times 10^{-3} \mathrm{~V}-3.807 \times 10^{-3} \mathrm{~N}-\mathrm{m}$. The error bars represent $\pm 3 \%$ uncertainty in the data.

time the torque sensor was moved. To obtain the calibration curve, a known torque was applied to the motor and the bridge voltage was recorded. The results of the calibration were recorded to text files using a LabVIEW program. To obtain a linear correlation between voltage and applied torque a MATLAB program was written to read the calibration data files. The calibration curve is plotted in Figure 2.9. The error bars represent the $\pm 3 \%$ uncertainty in the data. A calibration curve was generated in each row for every case. In Figure 2.9 the data obey the linear correlation $\mathrm{T}=5.717 \times 10^{-3} \mathrm{~V}-3.807 \times 10^{-3} \mathrm{~N}-\mathrm{m}$.

The experiment used 3 torque sensors during 13 case arrangements. One sensor measured torque while the rotor rotated in the clockwise direction. This sensor 
was mounted on a $12 \mathrm{~cm}$ mast and was primarily used to make measurements in the centerline of the array. A second sensor measured torque while the rotor rotated in the counterclockwise direction. It was also mounted on a $12 \mathrm{~cm}$ mast. The third sensor rotated in the clockwise direction and was mounted on the $18 \mathrm{~cm}$ mast. Before the collection of data, the 3 sensors were all mounted on the $12 \mathrm{~cm}$ masts and tested under the same conditions. The results of the torque sensor calibration will be discussed in the results section.

\subsection{Measuring angular velocity}

The rotors of the wind turbines in this experiment were a three-blade design. A piece of reflective tape was attached to one of the blades. A Monarch LED optical sensor (Model ROS-W) was used to measure the number of revolutions the reflective tape makes each second. An optical sensor measured the frequency of the rotors, which was averaged over one-minute intervals, and then converted into angular velocity with the conversion $\omega=2 \pi f$. The angular frequencies were recorded under these conditions and the uncertainty was calculated at peak power. The rotors of the three sensors were rotating at $(31.9 \pm 0.7) \mathrm{Hz}$. The uncertainty in the angular velocity measurement was $\pm 2 \%$.

A National Instruments (NI USB 6216) data acquisition board and a LabVIEW program were used to simultaneously record the acquired data from the torque sensors and the optical sensors. The signals from the optical sensors and the bridge voltage 
were recorded for one-minute intervals. The bridge voltage and the frequency of the rotor blades were recorded simultaneously at each load and the power was calculated.

The turbines were wired into a bread board and resistors were used to load the turbines. Resistors ranging from 2 to $100,000 \Omega$ were placed in the circuit with the turbines. The loads were applied to the turbines in the first row of the wind turbine array. A power curve was generated and the angular velocity that yields the maximum power was determined; then, the first row was fixed at the angular velocity yielding maximum power. Next, the torque sensor was moved to the second row of the wind turbine array, a power curve was generated, and the angular velocity was fixed at the maximum power. This process was repeated, such that all four rows were operating at maximum power. Mechanical torque on the turbine $T$ was recorded at 17 loads. The angular velocity of the rotor $\omega$, was calculated from the optical-sensor frequency signal and the mechanical power from the wind turbines was calculated using $P=T \times \omega$. The power extracted by the wind turbines was calculated in each of the 4 rows for every case. The inflow conditions at the front row were held constant for all of the experimental layouts. The data was then nondimensionalized where velocity measurements were obtained; these results will be plotted in the following sections. The inflow conditions were held constant: the mean hub-height velocity at the front row of turbines was $3.93 \mathrm{~m} / \mathrm{s}$ with a turbulence intensity of $15 \%$. The arrangements of the wind turbine arrays were the only conditions changed. The results presented in the following section are arranged according to the individual 


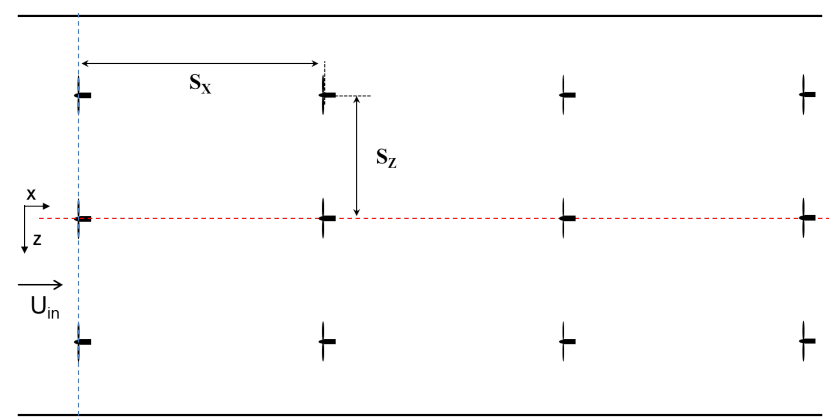

Figure 2.10: 10 cases are a 3 by 4 wind turbine array. The spacing variables $S_{X}$ and $S_{Z}$ change in Cases $1 \mathrm{~A}-1 \mathrm{C}$. Power measurements were obtained at the centerline in all 4 rows. Cases $3 \mathrm{~A}-3 \mathrm{C}$ and $4 \mathrm{~A}-4 \mathrm{C}$ had the same spacing as Case 1A.

cases.

\subsection{Experimental configurations}

Experiments were performed on wind turbine arrays arranged in 13 different cases.

Table 2.1 defines the parameters of Figure 2.10 that changed in Cases 1A-1D. Ten of the cases studied were arranged in a grid and their layouts are depicted in Figure

Table 2.1: In Cases 1A-1D variables $S_{X}$ and $S_{Z}$ define the downstream and transverse spacing for Figure 2.10. The rotor rotation was clockwise and the mast height was 1D.

\begin{tabular}{|c|c|c|c|c|}
\hline & \multicolumn{2}{|c|}{ Spacing } & \multicolumn{2}{c|}{ Centerline Effect } \\
\hline Case & $S_{X}$ & $S_{Z}$ & Rotation & Mast Height \\
\hline $1 \mathrm{~A}$ & $6 \mathrm{D}$ & $3 \mathrm{D}$ & $\mathrm{cw}$ & $1 \mathrm{D}$ \\
\hline 1B & $3 \mathrm{D}$ & $3 \mathrm{D}$ & $\mathrm{cw}$ & $1 \mathrm{D}$ \\
\hline 1C & $6 \mathrm{D}$ & $1.5 \mathrm{D}$ & $\mathrm{cw}$ & $1 \mathrm{D}$ \\
\hline 1D & $3 \mathrm{D}$ & $1.5 \mathrm{D}$ & $\mathrm{cw}$ & $1 \mathrm{D}$ \\
\hline
\end{tabular}


Table 2.2: In Cases 2A-2C variables $S_{X}$ and $S_{Z}$ define the downstream and transverse spacing for Figure 2.11. The rotor rotation was clockwise and the mast height was $1 \mathrm{D}$.

\begin{tabular}{|c|c|c|c|c|c|c|}
\hline & \multicolumn{2}{|c|}{ Spacing } & \multicolumn{4}{c|}{ Offset distance } \\
\hline Case & $S_{X}$ & $S_{z}$ & Row 1 & Row 2 & Row 3 & Row 4 \\
\hline 2A & $6 \mathrm{D}$ & $3 \mathrm{D}$ & $S_{1}=3 \mathrm{D}$ & $S_{2}=1.5 \mathrm{D}$ & $S_{1}=3 \mathrm{D}$ & $S_{2}=1.5 \mathrm{D}$ \\
\hline 2B & $6 \mathrm{D}$ & $3 \mathrm{D}$ & $S_{1}=1.5 \mathrm{D}$ & $S_{2}=3 \mathrm{D}$ & $S_{1}=1.5 \mathrm{D}$ & $S_{2}=3 \mathrm{D}$ \\
\hline 2C & $6 \mathrm{D}$ & $3 \mathrm{D}$ & $S_{1}=3 \mathrm{D}$ & $S_{2}=1.5 \mathrm{D}$ & $S_{1}=1.5 \mathrm{D}$ & $S_{2}=3 \mathrm{D}$ \\
\hline
\end{tabular}

2.10 .

In cases $2 \mathrm{~A}-2 \mathrm{C}$ the turbines are staggered in the rows. Their layout is depicted in Figure 2.11. The distance between the rows in Cases 2A-2B is $6 \mathrm{D}$. The distance from the centerline varied from $S_{1}=3 D$ to $S_{2}=1.5 D$ depending on the case. Table 2.2 defines the parameters of Figure 2.11 that changed in Cases 2A-2D. In the three staggered configurations all the turbine's mast had heights equal to $1 \mathrm{D}$ and the rotors rotated clockwise.

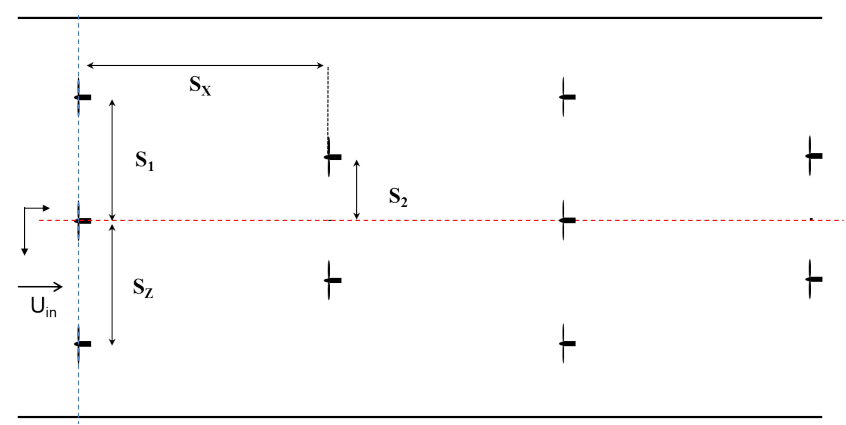

Figure 2.11: Depiction of the staggered wind turbine arrays. The variables $S_{1}$ and $S_{2}$ represent the offset distance from the centerline and $S_{X}$ and $S_{Z}$ downstream and transverse spacing respectively. 
Table 2.3: In Cases 3A-3C variables $S_{X}$ and $S_{Z}$ define the downstream and transverse spacing for Figure 2.10. The rotor rotation vaired depending on the Case and Row.

\begin{tabular}{|c|c|c|c|c|c|c|c|}
\hline & \multicolumn{2}{|c|}{ Spacing } & Mast Height & \multicolumn{4}{|c|}{ Rotation } \\
\hline Case & $S_{X}$ & $S_{Z}$ & All Rows & Row 1 & Row 2 & Row 3 & Row4 \\
\hline 3A & $6 \mathrm{D}$ & $3 \mathrm{D}$ & 1D & $\mathrm{ccw}$ & $\mathrm{cw}$ & $\mathrm{ccw}$ & $\mathrm{cw}$ \\
\hline 3B & $6 \mathrm{D}$ & $3 \mathrm{D}$ & 1D & $\mathrm{ccw}$ & $\mathrm{cw}$ & $\mathrm{ccw}$ & $\mathrm{cw}$ \\
\hline 3C & $6 \mathrm{D}$ & $3 \mathrm{D}$ & 1D & $\mathrm{ccw}$ & $\mathrm{ccw}$ & $\mathrm{ccw}$ & $\mathrm{ccw}$ \\
\hline
\end{tabular}

Cases $3 \mathrm{~A}-3 \mathrm{C}$ studied the effect of changing the rotational direction of the rotors. All turbines had 1D mast and were arranged according to the layout in Figure 2.10 with the same spacing as Case 1A. Table 2.3 defines the rotational direction of the rotor for Cases $3 \mathrm{~A}-3 \mathrm{C}$.

Case $4 \mathrm{~A}-4 \mathrm{C}$ were 3 cases that studied the effect of varying the mast height of the turbines. The arrangement of the tall and short masts are depicted in Figure 2.12 and had the same spacing as Case 1A. In Figure $2.12 H_{1}$ is a mast of height $1 \mathrm{D}$ and $H_{2}$ represents a mast height of $1.5 \mathrm{D}$. Case $4 \mathrm{~A}$ turbine array had tall masts in the first row. Case 4B had tall masts in the second row and Case $4 \mathrm{C}$ had tall and short masts arranged in a checkerboard pattern. Table 2.4 defines where the tall and short

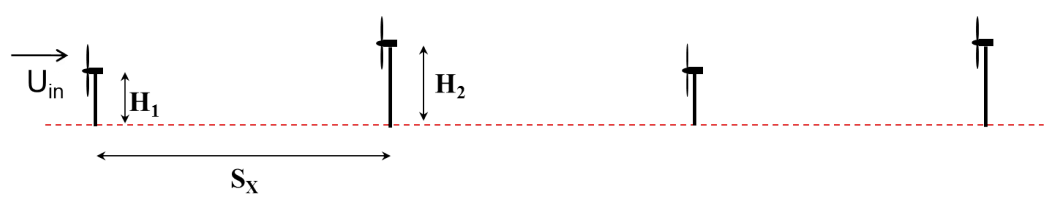

Figure 2.12: Description of the centerline profile of Case 4A-4C. $H_{1}$ represents the short mast and $\mathrm{H}_{2}$ represents the tall mast. The position of the tall and short masts changed for each of the three cases. 
Table 2.4: In Cases $4 \mathrm{~A}-4 \mathrm{C}$ variables $S_{X}$ and $S_{Z}$ define the downstream and transverse spacing for Figure 2.10. The mast height vaired depending on the Case and Row.

\begin{tabular}{|c|c|c|c|c|c|c|c|}
\hline & \multicolumn{2}{|c|}{ Spacing } & \multicolumn{5}{|c|}{ Centerline Effect } \\
\hline Case & $S_{X}$ & $S_{Z}$ & Rotation & Row 1 & Row 2 & Row 3 & Row4 \\
\hline 4A & $6 \mathrm{D}$ & $3 \mathrm{D}$ & $\mathrm{cw}$ & $1.5 \mathrm{D}$ & $1 \mathrm{D}$ & $1.5 \mathrm{D}$ & $1 \mathrm{D}$ \\
\hline 4B & $6 \mathrm{D}$ & $3 \mathrm{D}$ & $\mathrm{cw}$ & $1 \mathrm{D}$ & $1.5 \mathrm{D}$ & $1 \mathrm{D}$ & $1.5 \mathrm{D}$ \\
\hline $4 \mathrm{C}$ & $6 \mathrm{D}$ & $3 \mathrm{D}$ & $\mathrm{cw}$ & $1 \mathrm{Dw}$ & $1.5 \mathrm{D}$ & $1 \mathrm{D}$ & $1.5 \mathrm{D}$ \\
\hline
\end{tabular}

masts are located for Cases $4 \mathrm{~A}-4 \mathrm{C}$. 


\section{3 \\ Results}

The experiments conducted in this research monitored the mechanical power output from model turbines arranged in varying configurations in a wind tunnel. The configurations included changing the spacing, staggering, rotation, and mast heights within the arrays. The siting of the wind turbines was changed to examine the effects on the power output of the turbines. Power measurements were collected in the centerline of the array to reflect the conditions of the wind turbines situated in different configurations within a wind farm. The power was examined in arrays with different downstream and transverse spacing and the staggering of downstream wind turbines. Counter-rotating rotor blades were used in conjunction with clockwise-rotating rotors to measure whether momentum not absorbed by the clockwise-rotating rotor is available for the counter-rotating rotors. In addition, two mast heights were used in three of the experiment's cases. The combination of taller and shorter turbine masts has the potential for turbines to operate partially above or below the wake of the upstream turbines, allowing more energy to pass through the sweep of the rotors

downstream. This chapter discusses the results on power output caused by varying the spacing, staggering the configuration, counter-rotation of the rotors, and differing mast heights.

\subsection{Spacing Variation}

The results from changing the downstream spacing and transverse spacing are compared herein. The downstream and transverse spacing was changed in the four cases: 
Cases 1A, 1B, 1C, and 1D. The reader may refer back to Table 2.1 and Figure 2.10 for a picture of the different case variations. The front rows of all the configurations were placed in the same location the downstream turbines were arranged according to their case. The results from the four cases are plotted in Figure 3.1. Figure 3.1 plots mechanical power, in watts, extracted by the wind turbine versus the angular velocity. In all of the power curve figures, the $(\square)$ represents the first row, the (o) represents the second row, the $(\diamond)$ represents the third row, and the $(\triangle)$ represents the fourth row. In Figure 3.1, the maximum power in the first row of all the spacing variation cases is $0.14 \mathrm{~W}$ and occurs at $2000 \mathrm{rpm}$. The average hub-height velocity in front of the front row rotor was $3.93 \mathrm{~m} / \mathrm{s}$ and the turbulent intensity was $15 \%$. As expected, the first row extracts the most power from the flow.

Case 1A had turbines spaced 6D apart in the downstream direction. Figure 3.1a represents the power extracted in all the rows of Case 1A. The velocity deficit from the first row of turbines decreases the available power in the second row. In the second, third, and fourth rows of Case 1A the power was $43 \%$ less than the front row and the average hub-height velocity decreased $60 \%$ in the third row. In the third row the hub-height velocity was $3.30 \mathrm{~m} / \mathrm{s}$ and the turbulence intensity increased to $27 \%$. The reduced power in the third row is a result of the velocity deficit not being fully recovered. The maximum power coefficient in the first and third row was 0.33 and 0.31 respectively and occurs at a tip speed ratio of 3.1 .

Case 1B had downstream spacing of 3D. Figure 3.1b represents the power ex- 


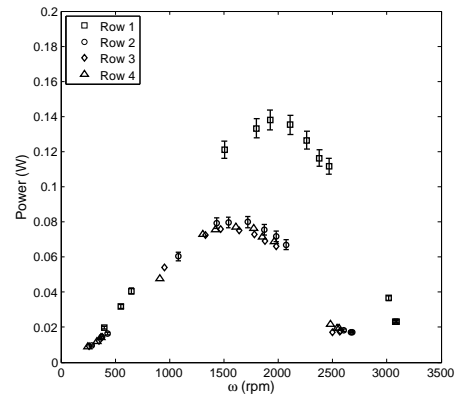

(a) Case $1 \mathrm{~A}, S_{X}=6 \mathrm{D}$ and $S_{Z}=3 \mathrm{D}$

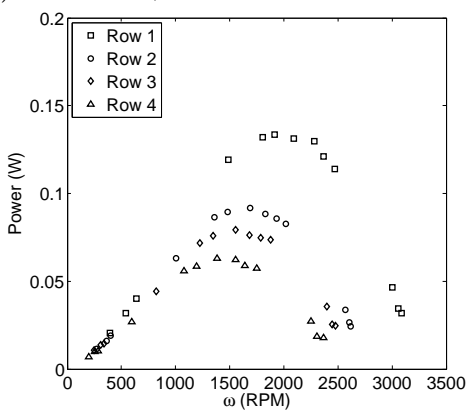

(c) Case $1 \mathrm{C}, S_{X}=6 \mathrm{D}$ and $S_{Z}=1.5 \mathrm{D}$

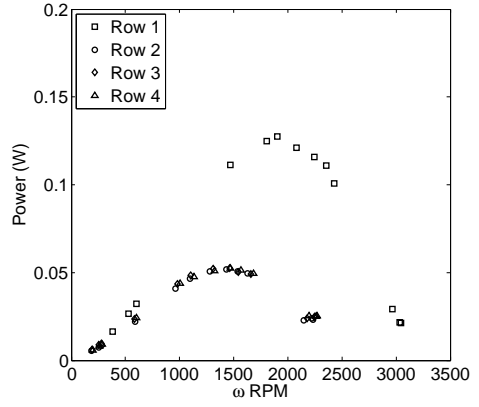

(b) Case $1 \mathrm{~B}, S_{X}=3 \mathrm{D}$ and $S_{Z}=3 \mathrm{D}$

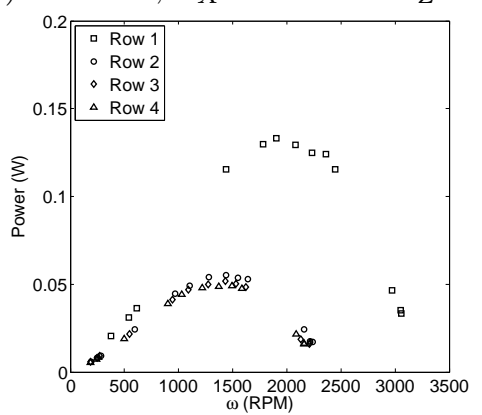

(d) Case $1 \mathrm{D}, S_{X}=3 \mathrm{D}$ and $S_{Z}=1.5 \mathrm{D}$

Figure 3.1: Mechanical power as a function of angular velocity. The error bar represents the $\pm 4 \%$ uncertainty of the data.

tracted in all of the rows of Case 1B. In the second, third, and fourth rows of Case $1 \mathrm{~B}$, power measurements showed that the power was $64 \%$ less than the front row. Due to the decreased spacing between the turbine rows, the velocity deficit has less space to recover compared to the $6 \mathrm{D}$ spacing. In Case 1B the average hub-height velocity in front of the rotor in the third row was $2.35 \mathrm{~m} / \mathrm{s}$. The turbulence generated by the upstream turbines has less time to disperse. The turbulence intensity in front of the third-row turbine was $32 \%$.

Similar to Case 1A, Case 1C had turbines spaced 6D downstream, but the trans- 
verse spacing was reduced to $1.5 \mathrm{D}$. Figure 3.1c represents the power extracted in all the rows of Case $1 \mathrm{C}$. In Case $1 \mathrm{C}$ the power decreases by $34 \%$ from the first to the second row. The second row of Case 1C extracted slightly more power than Case 1A. However, in the second and third row the power dropped another $12 \%$ and the power extracted was similar to Case $1 \mathrm{~A}$.

Case 1D was the most tightly arranged layout. Figure 3.1d represents the power extracted in all the rows of Case 1D. The power dropped $61 \%$ by the second row and did not vary in the subsequent rows downstream similar to Case 1B. Subtle effects in power were observed by reducing the transverse spacing compared to Case 1B. The average hub-height velocity in front of the rotor in the third row of Case 1D was 2.59 $\mathrm{m} / \mathrm{s}$ and the turbulence intensity was $37 \%$.

The power extracted by the wind turbines in the four cases varied depending

on their spacing. Case1A extracted the most power of the four cases. The power extracted in the cases with rows spaced 3D downstream was significantly reduced compared to the cases having 6D downstream spacing.

\subsection{Staggered Configuration}

The results from staggering the downstream turbines in the array are discussed and compared to the aligned Case 1A. Three staggered configurations were studied: Cases $2 \mathrm{~A}, 2 \mathrm{~B}$, and, $2 \mathrm{C}$. The rows were spaced $6 \mathrm{D}$ apart in the downstream direction, but the turbines were not placed directly in the wake of the upstream turbines (Refer 
to Figure 2.11 and Table 2.2 for the details). This effectively increased the spacing between turbines downstream compared to Case 1A.

Figure 3.2 plots power verses angular velocity for Case 2A and Case 2B. The symbols in figures represents, $(\square)$ the first row, (o) the second row, $(\diamond)$ the third row, and $(\triangle)$ the fourth row. The first row of case $2 \mathrm{~A}$ and $2 \mathrm{~B}$ extracted $0.13 \mathrm{~W}$ of power. The inflow conditions at the front were the same as the aligned cases. The average hub-height velocity was $3.93 \mathrm{~m} / \mathrm{s}$ and the turbulence intensity was $15 \%$. As expected the front row power equals that of Case 1A. In the second row the average hub-height velocity in front of the rotor was $3.83 \mathrm{~m} / \mathrm{s}$ and the turbulence intensity was $13 \%$. These conditions are similar to those observed in the front row. The effect of the wake from the first row on the staggered turbines in the second row is small. In the second row of Case $2 \mathrm{~A}$ and $2 \mathrm{~B}$ the power extracted was $1.3 \mathrm{~W}$ and was equal

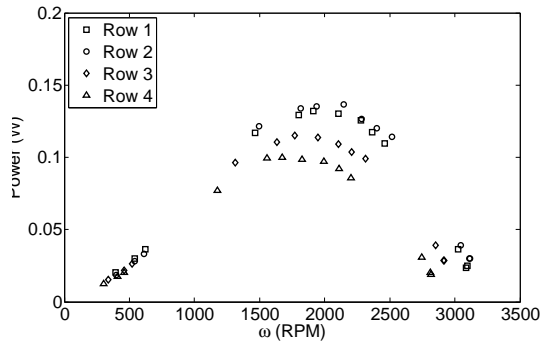

(a) Case $2 \mathrm{~A}, S_{X}=6 \mathrm{D}$ and $S_{Z}=3 \mathrm{D}$. $S_{2}=1.5 \mathrm{D}$ in the second and fourth rows

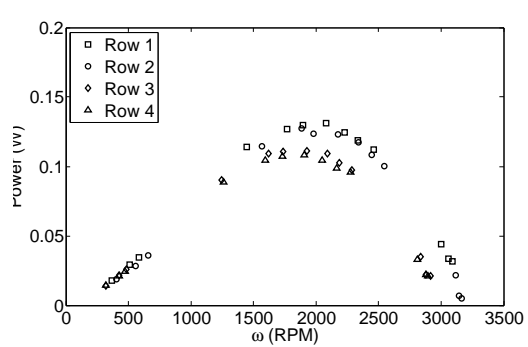

(b) Case 2B, $S_{X}=6 \mathrm{D}$ and $S_{Z}=3 \mathrm{D}$. $S_{2}=1.5 \mathrm{D}$ in the first and third rows

Figure 3.2: Power as a function of angular velocity comparing the power output of the 4 rows in Case 2A and Case 2B. 
to the power extracted in the front row. The power in the third and fourth rows of Case $2 \mathrm{~A}$ and $2 \mathrm{~B}$ decreased $23 \%$ compared to the front row. The power extracted in rows 3 and 4 was $25 \%$ higher than the power extracted in rows 3 and 4 of Case 1A. In the fourth row of Case $2 \mathrm{~A}$ the average hub height velocity was $3.76 \mathrm{~m} / \mathrm{s}$. The turbulence intensity in Case $2 \mathrm{~A}$ in the fourth row was $12 \%$ suggesting that staggering the siting of the turbines downstream allowed for more space for the turbulence to disperse and the wake to recover. Case 2B also had staggered turbines downstream but arranged in a different order. The power in the third and fourth rows was also increased but subtle differences were observed in the two cases, indicating that the different upstream conditions affect the wake downstream.

Case 2C was arranged differently than Case 2A and 2B. The turbines in rows 2 and 3 were offset from the centerline of the array by 1.5D. The first two rows of Case 2C were similar to Case 2A. Figure 2.11 and Table 2.3 describe the arrangement of

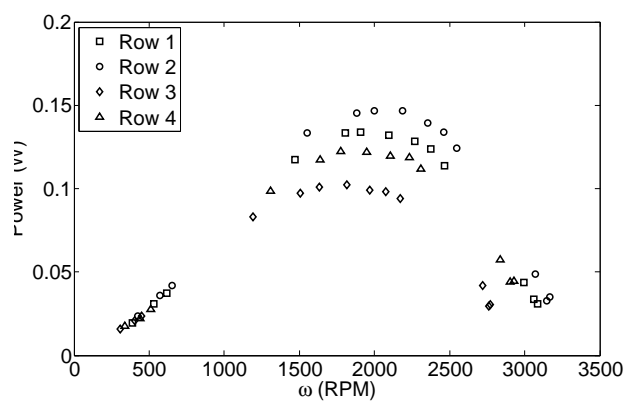

Figure 3.3: Power as a function of angular velocity comparing the power output of the 4 rows in Case $2 \mathrm{C}$ 
Case 2C. Essentially, there was 18D spacing between the turbines in the fourth row and the front row turbines. Figure 3.3 plots the the power extracted by the turbines in the 4 rows of Case $2 \mathrm{C}$. The third row and fourth row extracted $10 \mathrm{~W}$ and $12 \mathrm{~W}$ of power respectively. The hub-height velocity in front of the rotor in row 4 was 3.94 $\mathrm{m} / \mathrm{s}$ and a turbulence intensity was $14 \%$. These conditions are similar to the front row conditions. There is no presence of a velocity deficit in the fourth row of Case $2 \mathrm{C}$. The effects on the turbines downstream of the wake were limited when the turbines were in a staggered arrangement.

\subsection{Clockwise and Counterclockwise Configuration}

Cases 3A, 3B, and 3C involved blades that rotated in the clockwise and counterclockwise direction. In Case $3 \mathrm{~A}$ the rotors in the rows rotate in opposite directions. The rotors in the first and third rows rotate in the counterclockwise direction and the rotors in the second and fourth rotate in the clockwise direction. Figure 3.4a plots the power curves for the 4 rows of Case 3A. The maximum power extracted by the turbines in the first row of Case 3A was $0.13 \mathrm{~W}$. In Case 3A the second row's power dropped $15 \%$ to $0.11 \mathrm{~W}$. In the third and fourth rows the power decreased $38 \%$ from the front row which is similar to the third and fourth rows of Case 1A. The centerline of the array of Case 3B was similar to Case 3A, but the columns were arranged so that the rotors rotated in the opposite direction of the centerline rotors. Figure $3.4 \mathrm{~b}$

plots the power versus angular velocity for the 4 rows of Case 3B. The columns of 


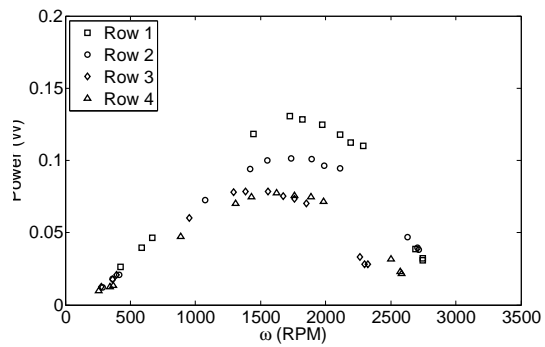

(a) Case $3 \mathrm{~A}, S_{X}=6 \mathrm{D}$ and $S_{Z}=3 \mathrm{D}$ the first and third rows rotate counterclockwise

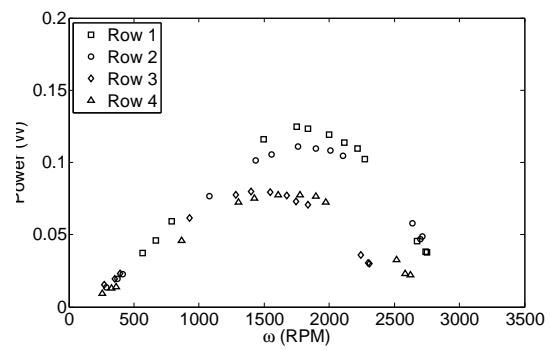

(b) Case $3 \mathrm{~B}, S_{X}=6 \mathrm{D}$ and $S_{Z}=3 \mathrm{D}$ the counter-rotating rotors are arranged in a checkerboard pattern

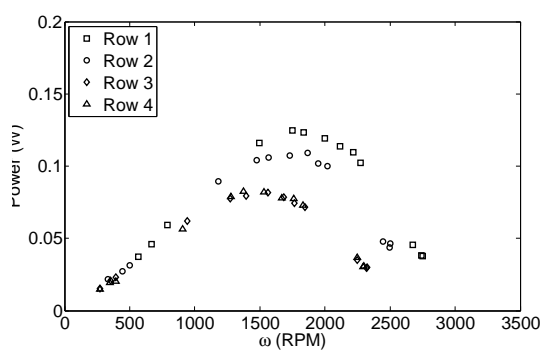

(c) Case $3 \mathrm{C}, S_{X}=6 \mathrm{D}$ and $S_{Z}=3 \mathrm{D}$ the centerline of the array had counter-rotating rotors; the outer columns were rotating clockwise.

Figure 3.4: Power as a function of angular velocity comparing the power output of the 4 rows in Case 3A, 3B, and 3C.

the wind turbine array in Case $3 \mathrm{C}$ rotated in opposite directions. Figure 3.4c plots the power in the four rows of Case 3C. Comparing Figure 3.4b and 3.4c no significant differences were observed. 


\subsection{Height Variation}

This section discusses the results of varying the heights of the wind turbines. Cases $4 \mathrm{~A}, 4 \mathrm{~B}$, and $4 \mathrm{C}$ had the same layout as Case $1 \mathrm{~A}$ with turbines spaced $6 \mathrm{D}$ downstream and 3D transverse. Case $4 \mathrm{~A}$ differs from Case $1 \mathrm{~A}$ in that tall masts were placed in the first and third rows. Figure 3.5a plots the power in the 4 row of Case $4 \mathrm{~A}$. The power extracted in the front row of Case $4 \mathrm{~A}$ was $0.2 \mathrm{~W}$. The higher power output is

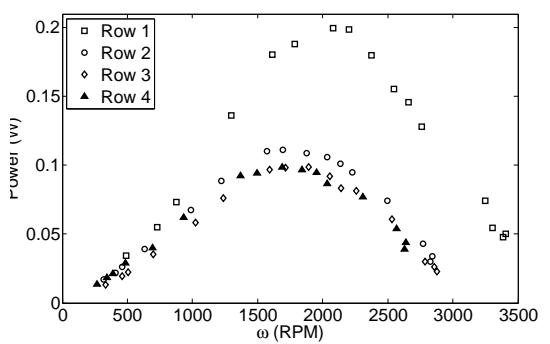

(a) Case $4 \mathrm{~A}, S_{X}=6 \mathrm{D}$ and $S_{Z}=3 \mathrm{D}$. Tall masts were in the first and third rows.

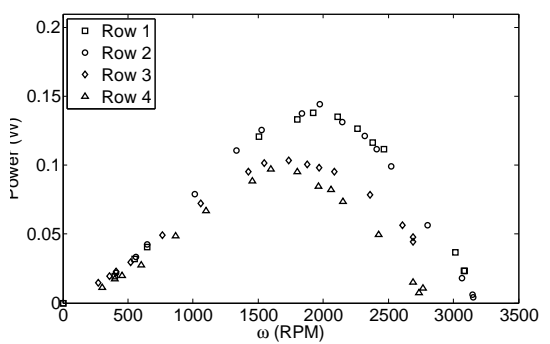

(b) Case $4 \mathrm{~B}, S_{X}=6 \mathrm{D}$ and $S_{Z}=3 \mathrm{D}$. Tall masts were in the second and fourth rows.

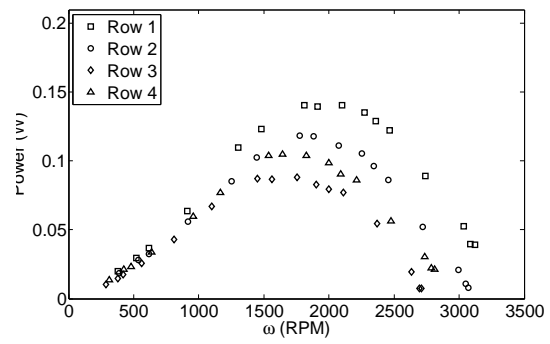

(c) Case $4 \mathrm{C}, S_{X}=6 \mathrm{D}$ and $S_{Z}=3 \mathrm{D}$. Tall masts were arranged in a checkerboard pattern.

Figure 3.5: Power as a function of angular velocity comparing the power output of the 4 rows in Case $4 \mathrm{~A}, 4 \mathrm{~B}$ and $4 \mathrm{C}$. 
expected because the turbines were operating higher in the boundary layer where the wind velocities are greater. The second row of Case $4 \mathrm{~A}$ peaked at $0.11 \mathrm{~W}$ and the third and fourth rows reached a maximum of $0.10 \mathrm{~W}$. Case $4 \mathrm{~B}$ had tall masts placed in the second and fourth rows of the array. Figure 3.5b plots the power in the 4 rows of Case 4B. The first and second rows had similar peak power and the peak in the third and fourth rows was $0.10 \mathrm{~W}$. Case $4 \mathrm{C}$ had a similar centerline profile as Case 4B; however, the layout of the array was arranged in a checkerboard configuration. Figure 3.5c shows that the maximum power in the first row was $0.14 \mathrm{~W}$ and only decreased $14 \%$ in the second row to $0.12 \mathrm{~W}$. The peak in the third row was $0.10 \mathrm{~W}$ and the fourth row peak was $0.09 \mathrm{~W}$.

\subsection{The Power Coefficient}

In this section the power coefficient $\left(C_{p}\right)$ and tip speed ratio $(\lambda)$ are compared for each of the 13 cases. The study compares the efficiency in the first and fourth rows of the different configurations. The front row is used as a bench mark; the rotors were optimized for these conditions. The fourth rows turbines are representative of a turbine positioned downstream in the wind turbine array. The effect on power efficiency is expected to change downstream in the array due of the different layouts.

In Figure 3.6 the maximum $C_{p}$ occurs at a tip speed ratio of 3.0. Depending on the design conditions of the rotor and the reference velocity used $\lambda_{\max }$ can vary. Adaramola 2011, estimated $\lambda_{\max }=6.0$ using a reference velocity of $11 \mathrm{~m} / \mathrm{s}$.In this 
study the reference velocity was measured $0.5 \mathrm{D}$ upstream of the turbine. Kang and Menevau 2010, used three reference velocities with $\lambda_{\max }$ ranging from 3.5 to 5.0. All of the rotor blades in this study were designed to achieve a maximum power coefficient of 0.32 with a hub-height velocity of $3.9 \mathrm{~m} / \mathrm{s}$ and a turbulence intensity of $12 \%$. As expected, there is little variability, because the average hub-height velocity was 3.93 $\mathrm{m} / \mathrm{s}$ for all of the front row turbines. The counter-rotating rotors and rotors mounted on the tall mast did not effect the wind turbine efficiency significantly. In all of the cases the blades stall at the same tip-speed ratio and cut out at $\lambda=5$. The scatter in the data in figure 3.6 may be a result in the small velocity fluctuations in the flow.

Figure 3.7 plots $\mathrm{Cp}$ versus $\lambda$ for fourth row of cases $1 \mathrm{~A}-1 \mathrm{D}$. In the figure, the $(\square)$ represents Case $1 \mathrm{~A}$, the $(\circ)$ represents Case $1 \mathrm{~B}$, the $(\diamond)$ represents Case $1 \mathrm{C}$,

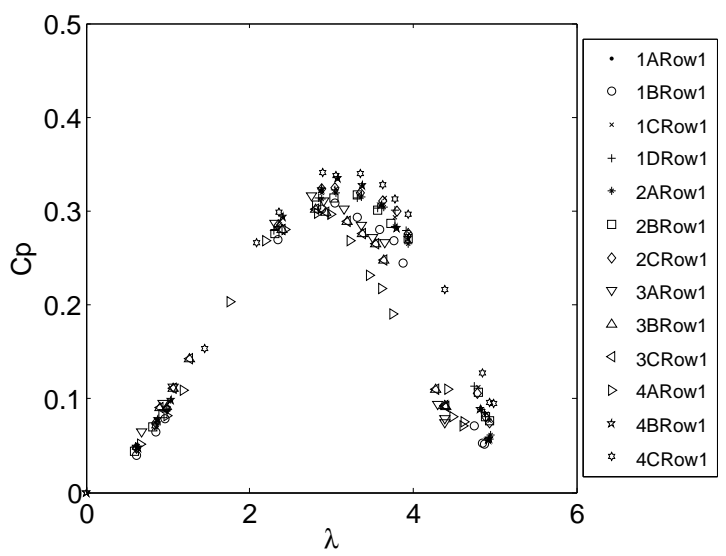

Figure 3.6: Power coefficient as a function of tip-speed ratio comparing the turbine efficiency of the front row turbines from all the cases. 
and the $(\triangle)$ represents Case 1D. In Figure 3.7 Significant differences are observed in the cases with $6 \mathrm{D}$ downstream spacing and the cases with 3D downstream spacing. Case $1 \mathrm{~A}$ and $1 \mathrm{C}$ had a maximum $C_{p}$ equal to 0.31 . Case $1 \mathrm{~B}$ efficiency was $20 \%$ lower and Case 1D was 20\% higher than Cases 1A and 1C. In Case 1B and 1D the downstream spacing between turbines was 3D; therefore, the turbines operating in the wake before it had sufficient space to recover. In both Case $1 \mathrm{~B}$ and $1 \mathrm{C}$ there were large velocity fluctuations and the the turbulence intensity was 34\%. The power coefficient is normalized by the mean hub-height velocity and in situations where there are large velocity fluctuations, the accuracy of the power coefficient could be called into question.

Figure 3.8 plots $C_{p}$ versus $\lambda$ for the three staggered cases comparing their fourth

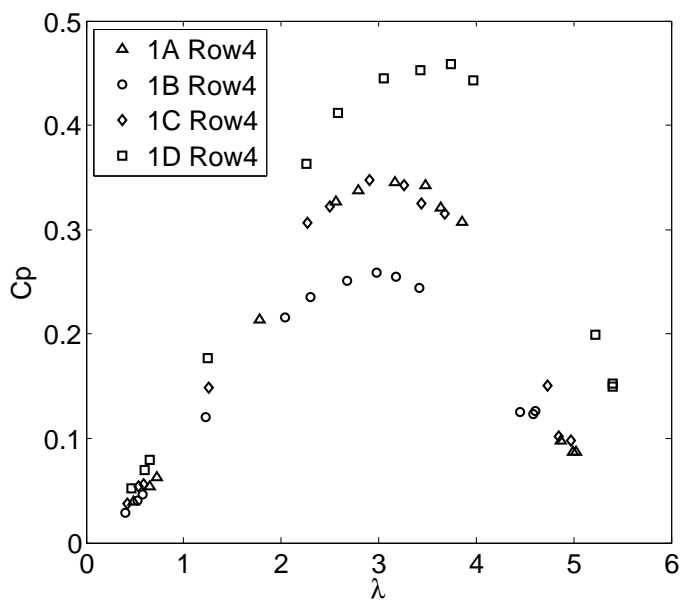

Figure 3.7: Power coefficient as a function of tip-speed ratio comparing the turbine efficiency in the fourth row of Cases 1A-1D 


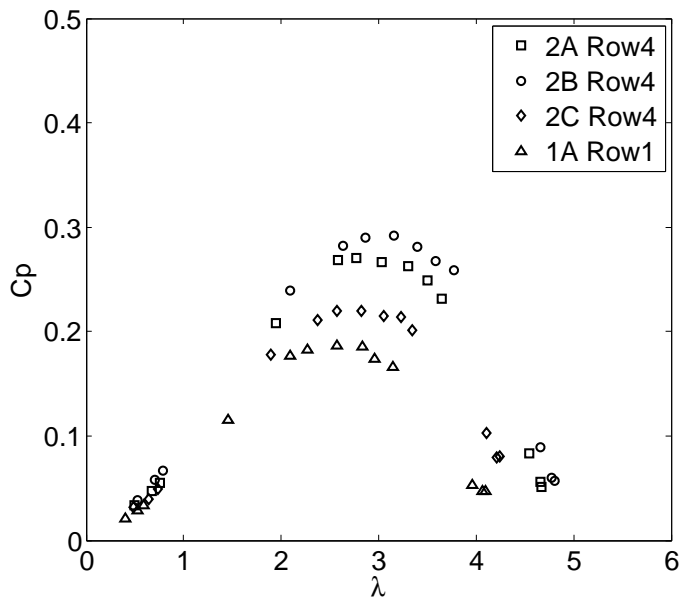

Figure 3.8: Power coefficient as a function of tip-speed ratio comparing the turbine efficiency in the fourth row of Cases 2A-2C. The fourth row of Case 1A is represented by the $(\triangle)$ and added for comparison.

rows. In the figure, the $(\square)$ represents Case 2A, the (o) represents Case 2B, the $(\diamond)$ represents Case 2C. In Figure 3.8 the $(\triangle)$ represents the fourth row of Case 1A and is added for comparison. The maximum $C_{p}$ in the fourth row of Case 1A was 0.18. All of the staggered cases had higher power coefficients. Case 2B turbines had a maximum $C_{p}$ equal to 0.30 . Case $2 \mathrm{~A}$ maximum $C_{p}$ was 0.29 and Case $2 \mathrm{C}$ was $20 \%$ lower with a maximum efficiency of 0.22 . The higher efficiency is due to the conditions at the fourth row. The staggered cases had conditions closer to the design conditions of the rotor, whereas in Case 1A the turbines were affected by the wake from the turbines upstream.

Figure 3.9 plots $\mathrm{Cp}$ versus $\lambda$ for two of the counter-rotating rotor cases comparing the fourth row. The fourth row of Case 1A is added to compare how the efficiency 


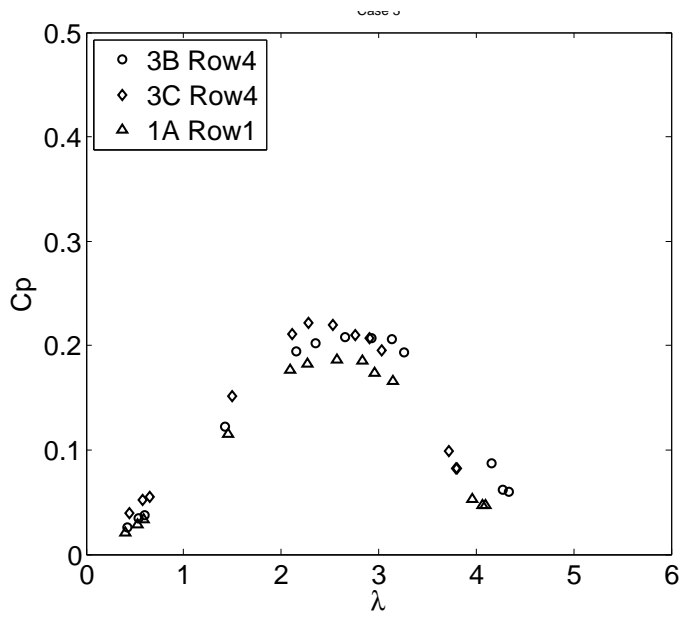

Figure 3.9: Power coefficient as a function of tip-speed ratio comparing the turbine efficiency in the fourth row of Cases 3B and 3C. The fourth row of Case 1A is represented by the $(\triangle)$ and added for comparison.

changes form the design conditions and represented by the $(\triangle)$ for comparison. The results are similar; this is primarily due to the spacing. Case $1 \mathrm{~A}$ had $6 \mathrm{D}$ by $3 \mathrm{D}$ spacing and Cases 3B and 3C had the same spacing. The observable differences are likely the result of the counter-rotating rotors used in Case 3B and 3C. In Figure 3.9 the maximum $\mathrm{Cp}$ is 0.21 and occurs at a tip speed ratio of 2.6.

Figure 3.10 plots $\mathrm{Cp}$ versus $\lambda$ for the three cases that had masts with different heights. Again, the fourth row of Case 1A is added for comparison (represented by the $(\triangle)$ ). In Figure 3.10 all of the data collapses and there is no significant difference in efficiency in the cases with the tall masts. The efficiency of the three cases is much greater than Case 1A. This increase in efficiency is due to the turbines' ability to 


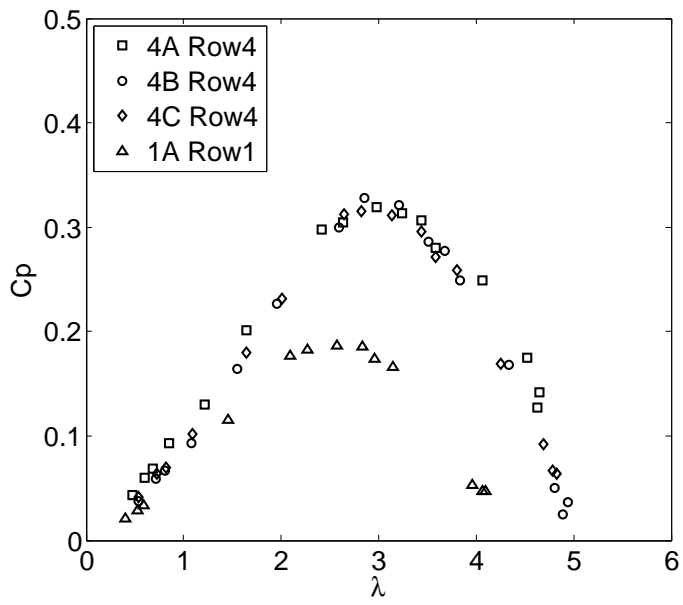

Figure 3.10: Power coefficient as a function of tip-speed ratio comparing the turbine efficiency of the fourth rows of Cases $4 \mathrm{~A}-4 \mathrm{C}$. The fourth row of Case $1 \mathrm{~A}$ is represented by the $(\triangle)$ and added for comparison.

extract energy from the flow above and below the wake of the turbines upstream. The efficiency of the fourth row turbines (with a mix of tall and short masts) is similar to that of the front row turbines.

\subsection{Wind Farm Efficiency}

In this section, the sum of power output from the turbines in the model wind farm is compared with the power output obtained if they were operating in an unobstructed environment. To calculate overall wind farm efficiency, Equation (1.6) was used. Figure 3.11 plots the overall wind farm efficiency versus the case number identifying the layout of the wind farm. The error bars in the figure are included to indicate $\pm 5 \%$ 
uncertainty in the data. The error was estimated from all of the data at maximum power. Case $1 \mathrm{~A}$ and Case $1 \mathrm{~B}$ had a wind farm efficiency of $67 \%$ and $56 \%$ respectively. This result is consistent with the observations made by Adaramola and Krogstad, who studied two wind turbines spaced 6D and 3D apart (Adaramola \& Krogstad, 2011). In this experiment, the rows in Case $1 \mathrm{C}$ were spaced $6 \mathrm{D}$ apart and had a wind farm efficiency of $68 \%$. The rows in Case 1D were spaced 3D apart and had a wind farm efficiency of $54 \%$. The efficiency of the wind farm is observed to depend strongly on the downstream separation distance of the turbines. No significant changes in the wind farm efficiency were observed by reducing the transverse spacing of the columns in the wind farm.

The rows in Cases 2A, 2B, and 2C are spaced 6D apart downstream and the adjacent turbine was separated by $3 \mathrm{D}$. Two of the rows had turbines offset by $1.5 \mathrm{D}$ from the centerline. Cases $2 \mathrm{~A}$ and $2 \mathrm{~B}$ had a wind farm efficiency of $91 \%$. Case 2C farm efficiency was $94 \%$. The increase in efficiency suggests that the wake from the upstream wind turbines has a minimal effect on the downstream wind turbines in the staggered layouts. Offsetting the wind turbines in wind farms effectively increases the downstream spacing to $12 \mathrm{D}$ and creates a more optimal wind farm. Meyers and Meneveau found that the optimal average turbine spacing may be on the order of 15D (Meyers \& Meneveau, 2012).

The rows in Cases 3A, 3B, and 3C were spaced 6D apart downstream and the columns were separated by 3D. The layout is the same as Case 1A: the only changes 


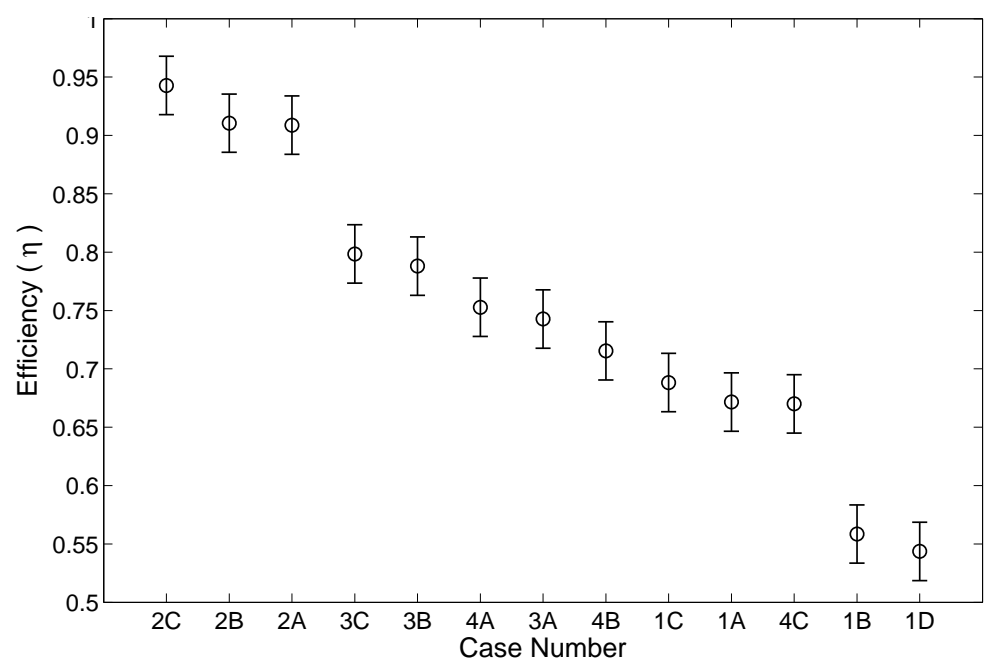

Figure 3.11: Overall wind farm efficiency of the 13 experimental layouts. Error bars indicate $\pm 5 \%$ uncertainty in the data.

were the rotational direction of the rotors. The wind farm efficiency of Case $3 \mathrm{~A}$ was $72 \%$. The wind farm efficiency of Cases 3B and 3C was $78 \%$ and $80 \%$ respectively. The data suggest that the rotational direction of the adjacent wind turbines can significantly affect the power the wind farm extracts.

The rows in Cases $4 \mathrm{~A}, 4 \mathrm{~B}$, and $4 \mathrm{C}$ were spaced $6 \mathrm{D}$ apart downstream and the columns were separated by $3 \mathrm{D}$. The layout is the same as Case 1A: the only changes were the height and placement of the tall masts. The wind farm efficiency of Case 4A was $75 \%$, with tall masts in the first and third rows. The wind farm efficiency of Case $4 \mathrm{~B}$ was $71 \%$, with tall masts in the second and fourth rows. Case $4 \mathrm{C}$ had a wind farm efficiency of $67 \%$, with tall masts in the second and fourth rows and tall 
masts adjacent to short masts in the rows. Case 4C presented the same efficiency as Case 1A, in which all of the masts were short. The data suggest that the order and placement of the tall masts affect the wind farm efficiency. 


\section{4 \\ Conclusion}

The torque and frequency of the rotor blades was measured in the first, second, third, and fourth rows of a wind turbine array under different configurations. The power was calculated in the four rows along the centerline of the wind array. The mechan-

ical power was calculated over a range of electrical loads to yield a full power curve, which was used to examine the performance of the wind turbines. PIV was used to characterize the velocity in front of each torque sensor. The mean hub-height velocity, the power coefficient, and tip speed ratios were obtained in all of the 13 cases. The data was plotted as of function of power versus angular velocity and the rows and cases were compared.

The study examined the power extracted by model wind farms arranged in different configurations with $12 \mathrm{~cm}$ and $18 \mathrm{~cm}$ masts. Mechanical power was measured to study how wind farm efficiency can be improved by changing turbine placement in a wind farm array. Four in-line spacing configurations were examined in the experiments. The power was calculated over a range of loads to obtain power curves in all 4 rows of the different layouts. The data suggest that decreasing the spacing from $6 \mathrm{D}$ to $3 \mathrm{D}$ in the in-line cases decreased the overall efficiency of the wind farm by $19 \%$.

The array was also arranged in 3 different staggered configurations with rows offset by $1.5 \mathrm{D}$ from the centerline. Offsetting the downstream position by $1.5 \mathrm{D}$ in the transverse direction increased the wind farm efficiency by $36 \%$ compared to the $6 \mathrm{D}$ by $3 \mathrm{D}$ in-line case (Case 1A). Staggering the wind array allowed more space for the 
velocity deficit to recover and the turbulence to decay.

This study also investigated the effect of increasing the height of the masts. The experimental results showed that the placement of the tall and short masts does affect the amount of power that is extracted. The velocity deficit of the short and tall masts affect the power of the downstream turbines, but placing the tall mast in front of the short mast has a greater effect on power. The tall and short mast configurations had a range of wind farm efficiencies between $67 \%$ and $75 \%$. The turbine efficiency in the fourth row of the hight cases was similar to the front row of the array.

Rotor blades were twisted to rotate clockwise and counterclockwise and 3 configurations of varying row and column rotations were studied. The effect of changing the rotational direction improved the wind farm efficiency compared to the clockwise rotating case with the same spacing. This effect was observed in Case 3C, which consisted of adjacent columns of wind farm turbines rotating in opposite directions. The efficiency of Case 3C was $80 \%$, which is an improvement of $20 \%$ over the aligned, clockwise-rotating Case 1A, with the same spacing.

This experiment showed that varying the downstream spacing affects the power in the downstream rows. Small changes in power were observed when the transverse spacing was changed by 1.5D. In the staggered configurations, the momentum deficit generated by the turbine in front had a longer recovery length than the in-line array. The longer recovery length allowed more time for the flow to entrain kinetic energy from the freestream, which made more energy available to the downstream wind tur- 
bines.

In future work, a device similar to the torque sensor could be used to measure the thrust in the wind turbine, because the thrust coefficient is often used to describe the load on the turbine blades and the structural design of the turbine tower. Higher turbulence levels could be introduced to determine if the rotor blades are capable of extracting the turbulent energy. To study the effects of an accelerated flow or a decelerated flow in a wind farm, terrain could be simulated by imposing pressure gradients. Also, to obtain a better understanding of how the diurnal cycle affects a wind farm, a temperature gradient could be imposed across the model wind farm. 


\section{References}

Adaramola, M., \& Krogstad. (2011). Experimental investigation of wake effects on wind turbine performance. Renewable Energy, 36(8), 2078 - 2086.

Barthelmie, R., Pryor, S., \& Frandsen, S. (2010). Quantifying the impact of wind turbine wakes on power output at offshore wind farms. Journal of Atmospheric and Oceanic Technology, 27(8), 1302-1317.

Bartl, J., Pierella, F., \& Sætran, L. (2012). Wake measurements behind an array of two model wind turbines. Energy Procedia, 24(0), 305 - 312. (Selected papers from Deep Sea Offshore Wind Conference, Trondheim, Norway, 19-20 January)

Burton, T., Sharpe, D., Jenkins, N., \& Bossanyi, E. (2001). Wind energy handbook. In (p. 213). New York: John Wiley and Sons.

Cal, R. B., Lebrón, J., Castillo, L., Kang, H. S., \& Meneveau, C. (2010). Experimental study of the horizontally averaged flow structure in a model wind-turbine array boundary layer. Journal of Renewable and Sustainable Energy, 2(1), 013106.

Chamorro, L., \& Porté-Agel, F. (2009). A wind-tunnel investigation of wind-turbine wakes: Boundary-layer turbulence effects. Boundary-Layer Meteorology, 132, 129-149.

Şahin, A. D. (2004). Progress and recent trends in wind energy. Progress in Energy and Combustion Science, 30(5), 501 - 543.

Greenway, M. E. (1979). An analytical approach to wind velocity gust factors. Journal of Wind Engineering and Industrial Aerodynamics, 5, 61 - 91.

Hansen, K. S., Barthelmie, R. J., Jensen, L. E., \& Sommer, A. (2012). The impact of turbulence intensity and atmospheric stability on power deficits due to wind turbine wakes at horns rev wind farm. Wind Energy, 15(1), 183-196.

Kang, H. S., \& Meneveau, C. (2010). Direct mechanical torque sensor for model wind turbine. Measurement Science and Technology, 21(10), 105206.

Meyers, J., \& Meneveau, C. (2012). Optimal turbine spacing in fully developed wind farm boundary layers. Wind Energy, 15(2), 305-317.

Pope, S. B. (2000). Turbulent flows. In (pp. 36-40, 83,125). Cambridge, UK: Cambridge University Press.

Sørensen, J. N., \& Myken, A. (1992). Unsteady actuator disc model for horizontal axis wind turbines. Journal of Wind Engineering and Industrial Aerodynamics, $39(1-3), 139-149$.

Tennekes, H., \& Lumley, J. L. (1973). A first course in turbulence. In (pp. 7 ,70,230). Massachusetts and London: The MIT Press.

USDOE, N. R. E. L. (2008). 20\% wind energy by 2030: Increasing wind energys contribution to u.s. electricity supply. Washington, D.C.: U.S. Dept. of Energy, Energy Efficiency and Renewable Energy. 
Vermeer, L., Sørensen, J., \& Crespo, A. (2003). Wind turbine wake aerodynamics. Progress in Aerospace Sciences, 39(67), 467 - 510.

Wagner, R., Antoniou, I., Pedersen, S. M., Courtney, M. S., \& Jrgensen, H. E. (2009). The influence of the wind speed profile on wind turbine performance measurements. Wind Energy, 12(4), 348-362.

Wharton, S., \& Lundquist, J. K. (2012). Atmospheric stability affects wind turbine power collection. Environmental Research Letters, 7(1), 014005. 